\title{
CATÁLOGO DE LAS MUESTRAS DE FAUNA DE LA COMUNIDAD DE MADRID CONSERVADAS EN LA COLECCIÓN DE TEJIDOS Y ADN DEL MUSEO NACIONAL DE CIENCIAS NATURALES
}

\author{
I. Rey* y B. A. Dorda**
}

\begin{abstract}
RESUMEN
Este trabajo presenta el catálogo de muestras conservadas en la colección de Tejidos y ADN de las especies animales (vertebrados e invertebrados) de la Comunidad de Madrid. Se proporcionan los porcentajes frente al total de las muestras conservadas en la colección y las clases animales representadas. Esta información pone de manifiesto el esfuerzo que el Museo Nacional de Ciencias Naturales realiza para conservar a nivel genómico el mayor porcentaje posible de la diversidad actual de la Comunidad de Madrid.
\end{abstract}

Palabras clave: Catálogo, colección, tejidos, ADN, biodiversidad, Madrid.

\begin{abstract}
Catalogue of fauna samples from Comunidad de Madrid conserved in the collection of Tissues and DNA of the Museo Nacional de Ciencias Naturales

This work presents the catalogue of preserved samples of animal species (vertebrate and invertebrate) from Comunidad de Madrid kept in the Tissues and DNA Collection of the Museo Nacional de Ciencias Naturales. Percentages are shown, calculated against the total number of samples and animal class kept in the collection. This information shows the effort developed by the Museo Nacional de Ciencias Naturales to preserve at the genomic level the greatest possible level of genomic biodiversity in Comunidad de Madrid.
\end{abstract}

Keywords: Catalogue, collection, tissues, DNA, biodiversity, Madrid.

\section{Introducción}

El Museo Nacional de Ciencias Naturales (MNCN) custodia las más amplias colecciones de zoología de España, tanto en número de especímenes como en especies representadas, que se han ido acumulando a lo largo de su convulsa historia; esta situación le acredita como centro nacional de referencia de la diversidad biológica. Asimismo tiene como funciones principales las de adquirir, conservar, investigar, comunicar y exhibir para fines de estudio, educación y contemplación las colecciones de valor histórico, científico y técnico actuales y futuras que forman parte de su Patrimonio

* Colección de Tejidos y ADN, Museo Nacional de Ciencias Naturales, c/ José Gutierrez Abascal 2. 28006-Madrid. Spain. monrf3g@mncn.csic.es

* Colección de Tejidos y ADN, Museo Nacional de Ciencias Naturales, c/ José Gutierrez Abascal 2. 28006-Madrid. Spain. balvarez@mncn.csic.es 
Histórico Natural. Como parte del cumplimiento de estos objetivos es siempre grato, como en ocasiones anteriores (Rey et al., 2002), publicar catálogos que permiten que la comunidad científica y la sociedad en general conozcan y utilicen tanto el material que las colecciones públicas del MNCN pone a su disposición como, en este caso concreto, la información sobre las especies que habitan en la actualidad la Comunidad de Madrid (CM).

La colección de Tejidos y ADN es la colección científica más moderna del MNCN y centra su interés en la preservación de muestras para investigación molecular y de ecotoxicología. Creada el año 2002, custodia ADN y tejidos y en la actualidad cuenta con más de 30.000 muestras de una amplia representación de especies diferentes y mantiene actualizada su base de información para facilitar su uso y acceso a toda la comunidad científica, en una época de pérdida masiva de especies, tales esfuerzos son esenciales para preservar un registro tan completo como sea posible de la biodiversidad genómica.

Estudios de conservación de especies, identificación de poblaciones e individuos, taxonomía y filogenia, relaciones de parentesco y genealogías, además de epidemiología o toxicología pueden beneficiarse de esta colección, tanto en la actualidad como en el futuro, utilizando todo el potencial que puede ofrecer la tecnología genómica.

Los proyectos de investigación son la principal fuente de ingreso de muestras, pero además las donaciones realizadas por Centros de Recuperación de Especies Amenazadas de distintas administraciones públicas son un enriquecedor medio de aumento tanto del número de muestras como de la diversidad de especies. Estos centros han ido enviando tejidos (entre ellos sangre de especímenes vivos, por lo que esta colección, a diferencia de las demás, incluye muestras de ejemplares vivos) de los animales que reciben para ser curados y posteriormente liberados o bien de especímenes completos fallecidos, de los cuales se obtienen muestras de músculo u otros órganos. El Centro de Recuperación de Especies Amenazadas de la Comunidad de Madrid es uno de los donantes más importante para las colecciones de vertebrados del MNCN.

\section{Metodología}

Como la colección de Tejidos y ADN es de muy reciente creación, creemos conveniente indicar de forma somera qué la constituye y cómo funciona antes de pasar al catálogo propiamente dicho.
Las muestras de tejidos siguen fundamentalmente los siguientes estándares de admisión y protocolos de conservación (Barreiro et al., 1994).

Los métodos de conservación son: congelación a $-80^{\circ} \mathrm{C}$, inmersión en alcohol al $70 \%$ y liofilización. Si el tamaño y el estado de conservación del espécimen lo permiten se conservan muestras de un mismo ejemplar en cada una de estas formas. Cuando las vísceras y el tejido muscular están descompuestos se toman muestras de piel, plumas, escamas o restos óseos, las cuales se someten a un proceso de liofilización.

Las muestras donadas por proyectos de investigación o por científicos se mantienen en las mismas condiciones en que son donadas y sólo se admiten si están perfectamente documentadas y las condiciones de conservación son aceptables.

Se recogen muestras de todos los ejemplares de especies catalogadas en peligro de extinción, vulnerables o raras que llegan al MNCN desde Centros de Recuperación.

Se acumula un volumen significativo de muestras de una misma especie, tanto por población y sexo, como por método de conservación (congelación, en alcohol, liofilización). Para poder cumplir con este objetivo es imprescindible mantener actualizadas las bases de datos.

Se conservan especies foráneas o autóctonas obtenidas de zoológicos, cría en cautividad, decomisadas por autoridades administrativas y veterinarios.

Se conservan especies domésticas atendiendo al interés que puedan haber manifestado distintos usuarios como colecciones de comparación; exposiciones, docencia o programas públicos.

Las muestras se catalogan con un número correlativo (si de un espécimen se obtienen diferentes tejidos, todos ellos tienen el mismo número de catálogo) y se informatizan documentando una serie de campos habituales en la catalogación de colecciones y haciendo referencia inequívoca de la ubicación de los distintos depósitos (armarios, frigoríficos o congeladores, según la forma de conservación). Además, se incluye un campo que relaciona el número de catálogo de la colección de Tejidos con el resto del espécimen, si éste se conserva en otra colección del MNCN (piel naturalizada, esqueleto, fluido).

Sólo mediante la utilización de estos procedimientos y de la base de datos relacionada pueden obtenerse con comodidad y exactitud relaciones pormenorizadas de ejemplares de la colección o, como es el caso, catálogos de fauna procedente de áreas concretas. 


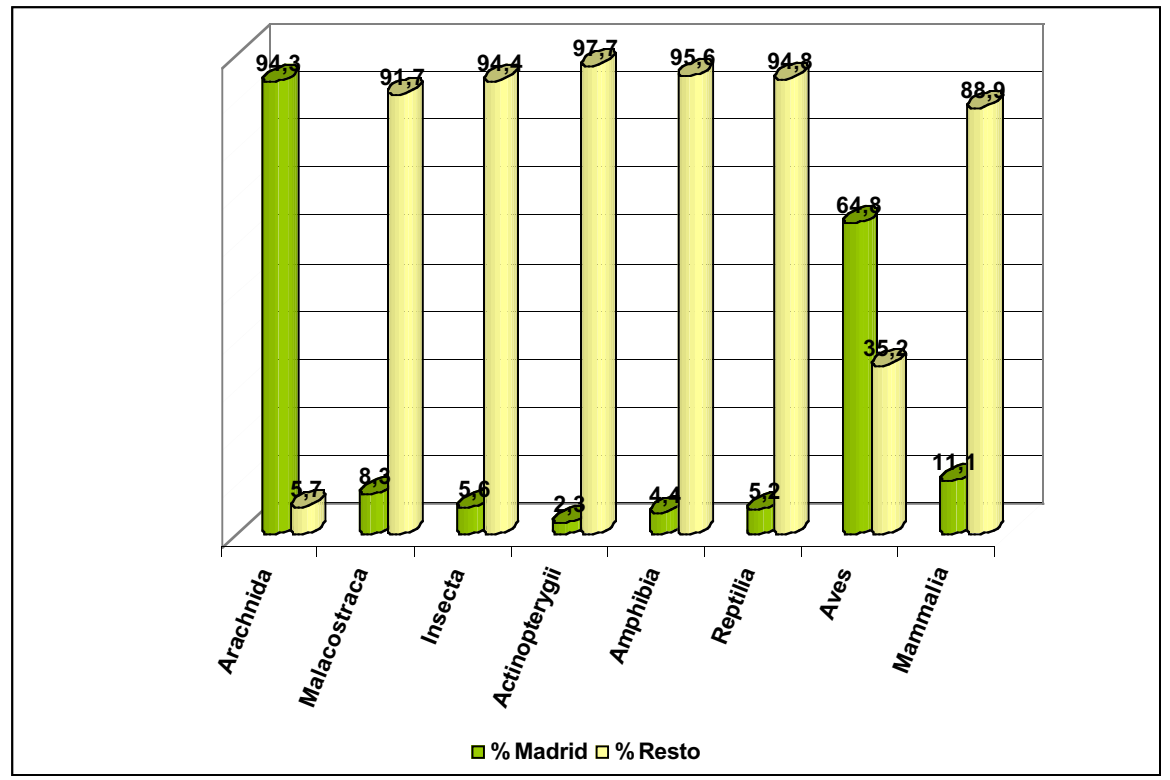

Fig. 1.- Porcentaje de muestras conservadas (tejido y ADN) de especies animales de la Comunidad de Madrid, frente al volumen total de la colección.

Fig. 1.- Percentage of conserved samples (tissues and DNA) of animal species in Comunidad de Madrid, as opposed to the total volume of the collection.

El catálogo completo de muestras conservadas en la Colección de Tejidos y ADN de la Comunidad de Madrid (Apéndice 1) se ha ordenado taxonómicamente hasta el nivel de familia, dentro de cada familia los géneros (y sus especies) se han dispuesto por orden alfabético; en cada especie los ejemplares se han colocado por orden numérico. La entrada de cada ejemplar incluye la siguiente información: $\mathrm{n}^{\mathrm{o}}$ de catálogo, localidad, fecha de captura y tipo de muestra conservada.

Para la ordenación taxonómica de los arácnidos se han seguido los trabajos de Valdecasas (1988, 2001) y Valdecasas \& Camacho (2006); para la clase Insecta, Martín-Piera \& Lopéz-Colón (2000) y Viñolas \& Cartagena (2005); de forma general para invertebrados se utilizan las paginas web http://faunaeur.org/ y http: //www.fauna-iberica.mncn.csic.es. La ordenación de los vertebrados sigue las siguientes obras: para los peces, Doadrio (2001) y http: //fishbase.org, para los anfibios y reptiles, Salvador (1998) y García-París et al. (2004); Howard \& Moore (1994) y Madroño et al. (2004), para las aves; y para los mamíferos, Wilson \& Reeder (1993).

\section{Resultados}

En la actualidad, en la colección de Tejidos y ADN hay muestras (de tejido, homogeneizados y ADN) de 2.111 especímenes colectados en el territorio de la CM. Esto representa el 13,5\% del total de 15.832 ejemplares conservados. Las muestras pertenecen a 8 clases animales (Fig. 1): arácnidos (99), malacostráceos (2), insectos (110), actinopterigios (120), anfibios (194), reptiles (22), aves (1.405) y mamíferos (159).

El número de muestras se distribuye en 1.900 de vertebrados frente a 211 de invertebrados (Fig. 2). Todos los grandes grupos de vertebrados están representadas frente a sólo 3 grupos de invertebrados: Arácnidos, Malacostráceos e Insectos (Fig. 1).

El porcentaje de muestras que se conserva en los distintos métodos está muy desequilibrado (Fig. 3), esto es debido a que durante los dos primeros años, se conservaban mayoritariamente en congelación. El ADN se conserva liofilizado o ultracongelado a $-80^{\circ} \mathrm{C}$. El tejido completo (sangre, piel, músculo, hígado, riñón, corazón en vertebrados o ejemplares completos cuando son invertebrados) se mantiene 


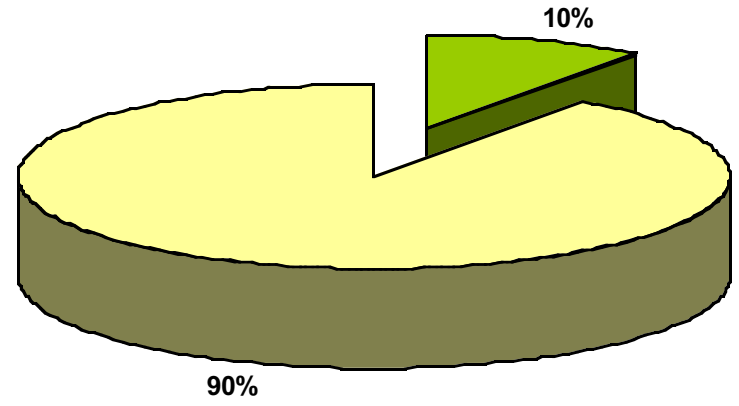

口Invertebrados

口Vertebrados

Fig. 2.- Porcentaje de muestras conservadas de vertebrados e invertebrados.

Fig. 2.- Percentage of conserved samples of vertebrates and invertebrates.

ultracongelado a la misma temperatura. En alcohol al $70 \%$, refrigerado a $5^{\circ} \mathrm{C}$ se preservan fragmentos de ejemplares como dedos o porciones de tejidos. Por último, pelo, plumas y también pequeñas porciones de tejido se guardan liofilizados.

\section{Discusión y Conclusiones}

Como se observa en la Fig. 1 el número de aves de la CM, 1.405 en total, es casi el doble que el recogido del resto de comunidades de España y este es el resultado obtenido como consecuencia de los acuerdos de colaboración establecidos con Centros de Recuperación de especies, fundamentalmente el Centro de Recuperación de Especies Amenazadas de Buitrago de Lozoya y el Centro de Recuperación de Rapaces Nocturnas (BRINZAL). Recopilar tejidos de cadáveres o de individuos que han estado enfermos y han sido recuperados (sangre o biopsias) es una tarea muy útil para poder obtener ADN no sólo en número sino también en diversidad. Es interesante hacer notar la abundancia relativa en la colección de algunas especies concretas: por ejemplo 50 especímenes de Apus apus, 91 de Ciconia ciconia, 57 de Buteo buteo, 137 de Falco tinnunculus, 255 de Passer domesticus, 79 de Athene noc- tua, 55 de Bubo bubo y 61 de Otus scops. Así por ejemplo, las muestras de gorrión común, Passer domesticus, fueron colectadas para un proyecto de investigación realizado desde 1993 a 1995 y posteriormente donadas por el investigador principal de dicho proyecto; pero el resto de las muestras citadas proceden de los centros de recuperación. Este hecho puede ser útil para conocer el porcentaje relativo de mortandad de dichas especies.

El número de mamíferos, 159 en total, tambien es elevado, un $11 \%$ del total, si lo comparamos con los porcentajes del resto de clases y esto se debe a la misma razón ya explicada para las aves, aunque en el caso de los mamíferos las especies amenazadas entran sólo desde uno de los centros y además son menos, tanto en número como en abundancia, que las de aves.

En la misma figura se observa que prácticamente la totalidad de las muestras de arácnidos, más concretamente ácaros acuáticos (99), han sido colectadas en la CM; esto se debe a que el grupo de investigación en acaros del MNCN ha depositado sus muestras de ADN en esta colección, tras un estudio de uso de especímenes conservados por distintos métodos clásicos para obtener ADN (Rey et $a l ., 2004)$. A pesar de que el porcentaje es muy elevado con respecto al total, el número de ejemplares 


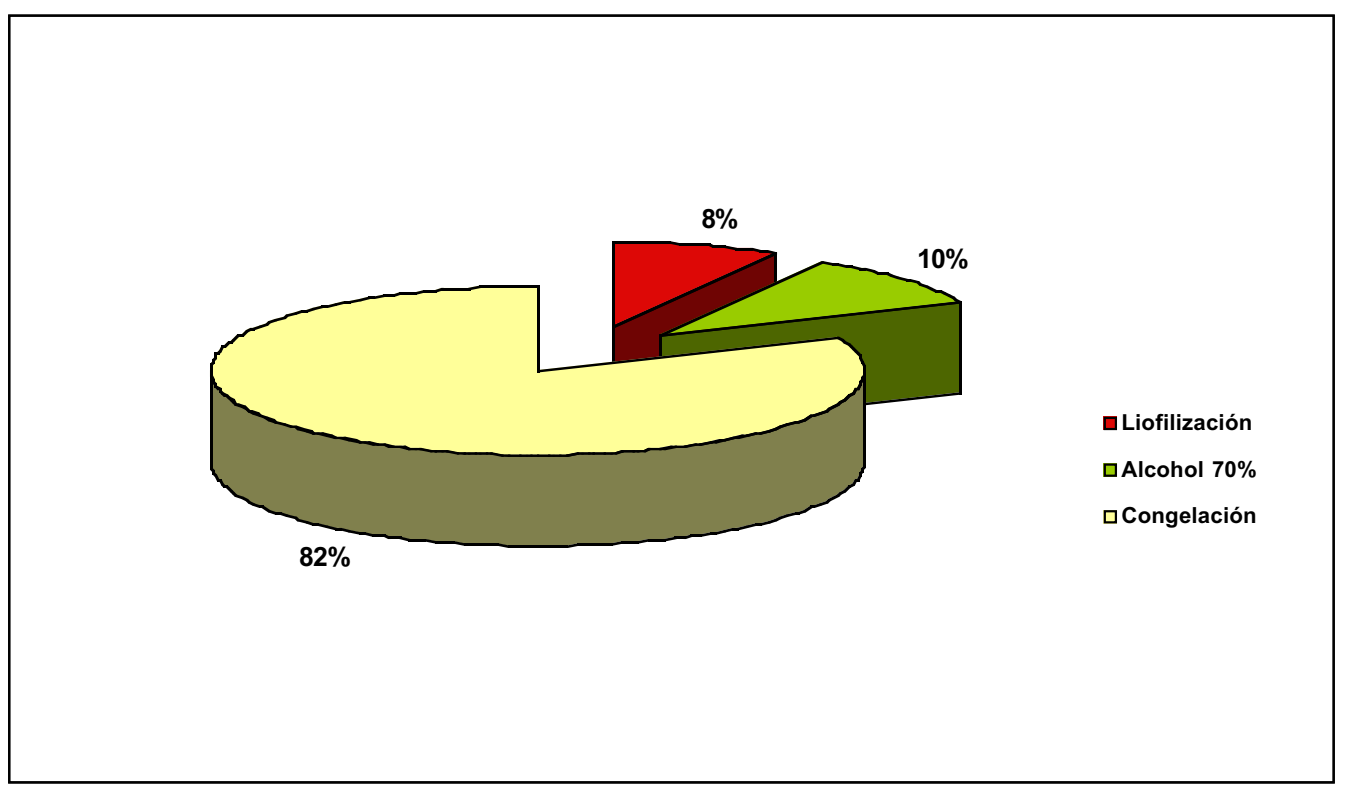

Fig. 3.- Porcentajes de muestras conservadas en los tres métodos más habituales.

Fig. 3.- Percentage of samples conserved following the three more habitual methods.

es muy pequeño y esto puede estar motivado por la relativa novedad de la colección y a la conservación con métodos tradicionales de las muestras. Esperamos que la publicación de trabajos como el presente anime a diferentes grupos de investigación a donar su material para incrementar el número de especies, principalmente de invertebrados, en los que aún la colección está probremente representada, tan sólo el $10 \%$ de los especímenes conservados (Fig. 2).

Como se puede observar, a pesar del número de registros, la fauna de la CM está escasamente representada a nivel molecular. Recordemos que esta colección pionera en Europa, tiene pocos años de existencia y sólo lentamente está siendo reconocida. $\mathrm{La}$ existencia de numerosos proyectos sobre fauna financiados por la CM nos hace ser optimistas y pensamos que en los próximos años este tipo de colecciones se verán incrementadas, lo cual redundará en el interés de esta colección para futuros estudios, tanto de gestión como de investigación básica. Además, su progreso hará posible estudiar la evolución de las poblaciones en el tiempo y evitará, en algunos casos, la alteración reiterada de poblaciones naturales por técnicas de muestreo. Es decir, si se conservan muestras de una población determinada obtenidas para una investigación ya concluida, su custodia garantizará la seguridad y disponibilidad de los remanentes de tejidos y ADN no utilizados previendo que esa población no tenga que volver a ser molestada y asegurando su comparación con poblaciones futuras.

Con el presente trabajo invitamos a la comunidad científica que investiga en fauna de la CM y del resto de España a que colaboren al crecimiento de esta colección.

\section{Referencias}

Barreiro. J., GonzÁlez FernÁndez, J. E. \& Rey-Fraile, I., 1994. Las colecciones de vertebrados: uso y gestión. In: B. Sanchiz (ed.). Manual de catalogación y gestión de las colecciones cientificas de Historia Natural. Manuales Técnicos de Museología. Vol. 5. Museo Nacional de Ciencias Naturales, CSIC. Madrid: 21-80.

DoAdrio, I. (ed.). 2001. Atlas y Libro Rojo de los Peces Continentales de España. Dirección General de Conservación de la Naturaleza-Consejo Superior de Investigaciones Científicas. Madrid. 364 pp.

García-París, M., Montori, A. \& Herrero, P. 2004. Amphibia, Lissamphibia. In: Ramos, M. A. et al. (Eds.). Fauna Ibérica, vol. 24. Museo Nacional de Ciencias Naturales, CSIC. Madrid. 640 pp. 
HOWARD, R. \& MOORE, A., 1994. A complete Checklist of the Birds of the World. $2^{\text {nd }}$ ed. Academic Press. London. $630 \mathrm{pp}$.

Madroño, A., Gonzalez, C. \& Atienza, J. C. (eds.) 2004. Libro Rojo de las Aves de España. Dirección General para la Biodiversidad-SEO. Madrid. 452 pp.

Martín-Piera, F. \& LóPez-Colón, J. I. 2000. Coleoptera, Scarabaeoidea I. In: Ramos, M. A. et al. (Eds.). Fauna Ibérica, vol. 14. Museo Nacional de Ciencias Naturales, CSIC. Madrid. 526 pp., 7 lám.

Rey, I., Fernández, J., Alonso Domínguez, M. S. \& Barreiro, J., 2002. Colección de mamíferos. In: Catálogo de las colecciones de Asia del Museo Nacional de Ciencias Naturales. III Vertebrados. Manuales Técnicos de Museología. Museo Nacional de Ciencias Naturales, CSIC. Madrid: 281-362.

Rey, I. Dorda B. A. \& Valdechasas A. G., 2004. Tradicional water mite fixatives and their compatibility with later DNA studies. Experimental and Applied Acarology, 34: 59-65.

Salvador, A., (CoOrdinador), 1998. Reptiles. In: Ramos, M. A. et al. (Eds.). Fauna Ibérica, vol. 10. Museo Nacional de Ciencias Naturales, CSIC. Madrid. 705 pp.
VALDECASAS, A. G., 1988. Lista sinonímica y bibliográfica de las hidracnelas (Acari, Hydrachnellae) de la Península Ibérica, Islas Baleares e Islas Canarias. Asociación Española de Limnología. Madrid. 81 pp.

VAldeCASAS, A. G., 2001. Water mites new for the Iberian Peninsula (Acari, Hydrachnellae). Graellsia, 57(1): 91-98.

Valdecasas, A. G. \& CAMAcho, A. I., 2006. Hydracnidia de la Comunidad de Madrid. Graellsia, 62(número extraordinario): 91-98.

Viñolas, A. \& Cartagena, M. C., 2005. Fauna de Tenebrionidae de la Peninsula Ibérica y Baleares. Vol. I. Lagriinae y Pimeliinae. Argania. Barcelona. $428 \mathrm{pp}$.

Wilson, D. E. \& ReEDER, D. M. (eds). 1993. Mammal Species of the World. $2^{\mathrm{a}}$ ed. Smithsonian Institution Press. Washington and London. 1206 pp. 
Apéndice 1.- Catálogo completo de muestras procedentes de la Comunidad de Madrid conservadas en la Colección de Tejidos y ADN del MNCN, ordenado taxonómicamente hasta familia.

Appendix 1. - Complete Catalogue of samples from Comunidad de Madrid preserved in the Tissues and DNA Collection (MNCN), arranged taxonomically down to family.

\section{ARACHNIDA}

\section{Orden PROSTIGMATA}

\section{Familia EYLAIDAE}

Género Eylais Latreille, 1796

MNCN/ADN: 10536, 10537. Río Lozoya. Canencia. Madrid. Octubre de 2001. ADN.

MNCN/ADN: 10538 al 10540. Río Lozoya. Canencia. Madrid. 27 de febrero de 2002 ADN.

Familia HYDRYPHANTIDAE

Género Protzia Piersig, 1896

MNCN/ADN: 10590. Río Lozoya. Canencia. Madrid. 21de marzo de 2002. ADN.

\section{Familia SPERCHONTIDAE}

Género Sperchon Kramer, 1877

MNCN/ADN: 10574. Río Lozoya. Rascafría. Madrid. 17de julio de 2002. ADN.

Sperchonopsis verrucosa (Protz, 1896)

MNCN/ADN: 10541 al 10543. De Rascafría a Cotos. Sierra de Guadarrama. Madrid. 16 de octubre de 2001. ADN.

Familia LEBERTIIDAE

Género Lebertia Neumann, 1880

MNCN/ADN: 10562, 10570. Río Lozoya. Canencia. Madrid. 21 de marzo de 2002. ADN

MNCN/ADN: 10587, 10588. Río Lozoya. Lozoya. Madrid. 25 de octubre de 2001. ADN.

MNCN/ADN: 10631. Río Lozoya. Rascafría. Madrid. 13 de julio de 2002. $\mathrm{ADN}$.

MNCN/ADN: 10636 al 10638. Río Jarama. Torrelaguna. Madrid. 2 de noviembre de 1978. ADN.

Familia TORRENTICOLIDAE

Género Torrenticola Piersig, 1896

MNCN/ADN: 10544,10546 al 10548, 10551 al 10553, 10563 al 10569 $10571,10589,10592$ al 10596, 10598, 10615 al 10619, 10621, 10622 Río Lozoya. Canencia. Madrid. 21de marzo de 2002. ADN

MNCN/ADN: 10554 al 10558, 10572, 10575 al 10581, 10599, 10600, 10624, 10626 al 10628. Río Lozoya. Rascafría. Madrid. 17 de julio de 2002. ADN.

MNCN/ADN: 10604 al 10608, 10629, 10630, 10632. Río Lozoya Rascafría. Madrid. 13 de julio de 2002. ADN.

MNCN/ADN: 10609 al 10613. Río Jarama. Torrelaguna. Madrid. 24 de agosto de 1978. ADN

MNCN/ADN: 10634. Río Jarama. Torrelaguna. Madrid. 2 de noviembre de 1978. ADN.

Familia HYGROBATIDAE

Género Atractides Koch, 1837

MNCN/ADN: 10545, 10550, 10591, 10597, 10614. Río Lozoya. Canencia. Madrid. 21 de marzo de 2002. ADN

MNCN/ADN: 10559 al 10561. Río Lozoya. Lozoya. Madrid. 25 de octubre de 2001. ADN.

MNCN/ADN: 10601, 10602, 10625. Río Lozoya. Rascafría. Madrid. 17de julio de 2002. ADN

Género Hygrobates Koch, 1837

MNCN/ADN: 10549, 10620. Río Lozoya. Canencia. Madrid. 21 de marzo de 2002. ADN.

MNCN/ADN: 10635. Río Jarama. Torrelaguna. Madrid. 2 de noviembre de 1978. ADN.
Familia ATURIDAE

Género Aturus Kramer, 1875

MNCN/ADN: 10573. Río Lozoya. Rascafría. Madrid. 17 de julio de 2002. ADN.

MNCN/ADN: 10623. Río Lozoya. Canencia. Madrid. 21 de marzo de 2002. ADN

MNCN/ADN: 10633. Río Lozoya. Rascafría. Madrid. 13 de julio de 2002. ADN.

\section{Orden ARANEAE}

Familia SEGESTRIIDAE

Segestria florentina (Rossi, 1790)

MNCN/ADN: 2107. Manjirón. Madrid. 6 de octubre de 2002. Tejido en alcohol.

\section{MALACOSTRACA}

\section{Orden BATHYNELLACEA}

Familia PARABATHYNELLIDAE

Hexaiberobathynella mateusi (Galhano, 1967)

MNCN/ADN: 8978, 8979. Río Jarama. Madrid. 19 de enero de 1988. $\mathrm{ADN}$

\section{INSECTA}

\section{Orden COLEOPTERA}

Familia MELOLONTHIDAE

Anoxia villosa (Fabricius, 1781)

MNCN/ADN: 3412, 3413. Collado Mediano. Madrid. Tejido congelado.

Rhizotrogus marginipes Mulsant, 1842

MNCN/ADN: 3406 al 3409. Collado Mediano. Madrid. 17 de abril de 2003. Tejido congelado.

Familia APHODIIDAE

Agolius bonvouloiri (Harold, 1860)

MNCN/ADN: 10503. Puerto de Navacerrada. Madrid. Tejido congelado.

Agrilinus constans (Duftschmid, 1805)

MNCN/ADN: 10504. Puerto de Navafría. Madrid. Tejido congelado.

Agrilinus rufus (Moll, 1782)

MNCN/ADN: 10505. Puerto de Navafría. Madrid. Tejido congelado.

Ammoecius frigidus Brisout, 1866

MNCN/ADN: 4666. Puerto de Navafría. Madrid. 14de mayo de 2000. Tejido congelado.

Aphodius conjugatus (Panzer, 1795)

MNCN/ADN: 10510. Guadarrama. Madrid. Tejido congelado.

Aphodius fimetarius (Linnaeus, 1758)

MNCN/ADN: 10511. Puerto de Navafría. Madrid. Tejido congelado.

Biralus satellitius (Herbst, 1789)

MNCN/ADN: 10513. Prádena del Rincón. Madrid. Tejido congelado.

Bodilus longispina (Küster, 1854)

MNCN/ADN: 10515. El Molar. Madrid. Tejido congelado. 
Colobopterus erraticus (Linnaeus, 1758)

MNCN/ADN: 10519. Puerto de Navacerrada. Madrid. Tejido congelado.

Esymus pusillus (Herbst, 1789)

MNCN/ADN: 4635. Puerto de Somosierra. Madrid. 12 de mayo de 2000. Tejido congelado.

MNCN/ADN: 4663. Puerto de Navafría. Madrid. 14 de mayo de 2000. Tejido congelado.

MNCN/ADN: 10521. Puerto de Navafría. Madrid. Tejido congelado.

Eurodalus coenosus (Panzer, 1798)

MNCN/ADN: 4664, 4665. Puerto de Navafría. Madrid. 14 de mayo de 2000. Tejido congelado.

Heptaulacus testudinarius (Fabricius, 1775)

MNCN/ADN: 10522. La Hiruela. Madrid. Tejido congelado.

Planolinus borealis (Gyllenhal, 1827)

MNCN/ADN: 10528. Puerto de Navafría. Madrid. Tejido congelado.

Subrinus sturmi (Harold, 1870)

MNCN/ADN: 10529. Aranjuez. Madrid. Tejido congelado.

\section{Familia GEOTRUPIDAE}

Geotrupes mutator (Marsham, 1802)

MNCN/ADN: 4570. Puerto de Navacerrada. Madrid. 14 de junio de 2000. Tejido congelado.

MNCN/ADN: 4627 al 4629. Puerto de Somosierra. Madrid. 12 de mayo de 2000. Tejido congelado.

Geotrupes stercorarius (Linnaeus, 1758)

MNCN/ADN: 4630, 4631. Puerto de Somosierra. Madrid. 12/05/2000.

MNCN/ADN: 4653, 4654. Puerto de Navafría. Madrid. 14 de mayo de 2000. Tejido congelado.

Typhaeus typhoeus (Linnaeus, 1758)

MNCN/ADN: 4563. Redueña. Madrid. 7de junio de 2000. Tejido congelado.

Familia SCARABAEIDAE

Bubas bubalus (Olivier, 1811)

MNCN/ADN: 4564. Redueña. Madrid. 7 de junio de 2000. Tejido congelado. MNCN/ADN: 4583, 4584. Redueña. Madrid. 9 de junio de 2000. Tejido congelado.

MNCN/ADN: 4604. Río Madarquillos. Madrid. 14 de junio de 2000. Tejido congelado.

Caccobius schreberi (Linnaeus, 1758)

MNCN/ADN: 4592. Quijorna. Madrid. 30 de mayo de 2000. Tejido congelado.

Copris hispanus (Linnaeus, 1764)

MNCN/ADN: 4562. Tres Cantos. Madrid. 27 de mayo de 2000.

Copris lunaris (Linnaeus, 1758)

MNCN/ADN: 4605. Río Madarquillos. Madrid. 14 de junio de 2000. Tejido congelado.

Euoniticellus fulvus (Goeze, 1777)

MNCN/ADN: 4582. Redueña. Madrid. 9 de junio de 2000. Tejido congelado. MNCN/ADN: 4585, 4586. Quijorna. Madrid. 30 de mayo de 2000. Tejido congelado.

Gymnopleurus flagellatus (Fabricius, 1787)

MNCN/ADN: 4598. El Molar. Madrid. Tejido congelado.

Gymnopleurus mopsus (Pallas, 1781)

MNCN/ADN: 4587. Quijorna. Madrid. 30 de mayo de 2000. Tejido congelado.

Liothorax muscorum Adam, 1994

MNCN/ADN: 10523. El Paular. Madrid. Tejido congelado.
Onitis belial Fabricius, 1798

MNCN/ADN: 4568. Tres Cantos. Madrid. Tejido congelado.

Onthophagus furcatus (Fabricus, 1781)

MNCN/ADN: 4646. Ontígola. Madrid 5 de mayo de 2000. Tejido congelado. MNCN/ADN: 4565. Redueña. Madrid. 07 de junio de 2000. Tejido congelado.

MNCN/ADN: 4590, 4591. Quijorna. Madrid. 30 de mayo de 2000. Tejido congelado.

MNCN/ADN: 4593, 4594. El Vellón. Madrid. 07 de junio de 2000. Tejido congelado.

Onthophagus lemur (Fabricius, 1781)

MNCN/ADN: 4597. El Vellón. Madrid. 07 de junio de 2000. Tejido congelado.

MNCN/ADN: 4606. El Vellón. Madrid. Tejido congelado.

MNCN/ADN: 4607. Prádena del Rincón. Madrid. 14de junio de 2000. Tejido congelado.

Onthophagus merdarius Chevrolat, 1865

MNCN/ADN: 4647 al 4650. Ontígola. Madrid. 5 de mayo de 2000. Tejido congelado.

Onthophagus similis (Scriba, 1790)

MNCN/ADN: 4595, 4596. El Vellón. Madrid. 7 de junio de 2000. Tejido congelado.

Onthophagus stylocerus Graells, 1859

MNCN/ADN: 4569, 4657 al 4662. Puerto de Navacerrada. Madrid. 14 de junio de 2000. Tejido congelado.

MNCN/ADN: 4657. Puerto de Navafría. Madrid. 14 de mayo de 2000. Tejido congelado.

Onthophagus taurus (Schreber, 1759)

MNCN/ADN: 4566, 4567. Redueña. Madrid. 7 de junio de 2000. Tejido congelado.

MNCN/ADN: 4580, 4581. Redueña. Madrid. 9 de junio de 2000. Tejido congelado.

MNCN/ADN: 4588, 4589. Quijorna. Madrid. 30de mayo de 2000. Tejido congelado.

MNCN/ADN: 4651. Ontígola. Madrid. 5 de mayo de 2000. Tejido congelado.

MNCN/ADN: 4571, 4572. Ontígola. Madrid. 29 de mayo de 2000. Tejido congelado.

Onthophagus vacca (Linnaeus, 1767)

MNCN/ADN: 4579. Arroyo Las Cañas. Madrid. 10 de junio de 2000. Tejido congelado.

MNCN/ADN: 4608. Prádena del Rincón. Madrid. 14 de junio de 2000. Tejido congelado.

MNCN/ADN: 4632 al 4634. Puerto de Somosierra. Madrid. 12 de mayo de 2000. Tejido congelado.

Familia TENEBRIONIDAE

Género Pimelia Fabricius, 1775

MNCN/ADN: 790 al 793. Cerro San Pedro. Madrid. 23 de abril de 1995. Tejido congelado.

MNCN/ADN: 903 al 913. Brunete. Madrid. 6 de mayo de 1995. Tejido congelado.

Pimelia baetica Solier, 1836

MNCN/ADN: 1093. Chinchón. Madrid. 18 de abril de 1995. Tejido congelado.

Pimelia castellana Pérez Arcas, 1865

MNCN/ADN: 736. Buitrago de Lozoya. Madrid. 5 de abril de 1996. Tejido congelado.

MNCN/ADN: 1074. Navalagamella. Madrid. 19 de marzo de 1995. Tejido congelado.

MNCN/ADN: 1084. Puerto de Malagón 2. Madrid. 20 de marzo de 1995. Tejido congelado.

Pimelia punctata Solier, 1836

MNCN/ADN: 1088, 1089. Rivas de Jarama. Madrid. 18 de marzo de 1995. Tejido congelado.

MNCN/ADN: 1090 al 1092. La Flamenca - Aranjuez. Madrid. 18 de marzo de 1995. Tejido congelado. 


\section{Orden ORTHOPTERA}

Familia ACRIDIDAE

Anacridium aegyptium (Linnaeus, 1764)

MNCN/ADN: 10219. Coslada. Madrid. 24 de octubre de 2001. Tejido congelado.

\section{Familia TETTIGONIIDAE}

Tettigonia viridissima (Linnaeus, 1758)

MNCN/ADN: 10095. Collado Mediano. Madrid. 08 de julio de 2002. Tejido liofilizado.

\section{Orden MANTODEA}

Familia MANTIDAE

Mantis religiosa (Linnaeus, 1758)

MNCN/ADN: 4174. Madrid. 1de noviembre de 2003. Tejido congelado.

\section{ACTINOPTERYGII}

\section{Orden CYPRINIFORMES}

Familia CYPRINIDAE

Rutilus arcasii (Steindachner, 1866)

MNCN/ADN: 1756. Río Santa Ana (confluencia río Lozoya). Cuenca Tajo. Alameda del Valle. Madrid. 22 de abril de 1996. Tejido congelado.

MNCN/ADN: 1757, 1758. Río Guadarrama. Batres. Madrid. 22de febrero de1996. Tejido congelado.

Tropidophoxinellus alburnoides (Steindachner, 1866)

MNCN/ADN: 14433 al 14445. Río Jarama (Cuenca Tajo). Patones. Madrid. 21 de abril de 1992. Tejido congelado

\section{Familia COBITIDAE}

Cobitis calderoni Bacescu, 1962

MNCN/ADN: 10101, 10102. Río Lozoya. Madrid. 18 de junio de 1991. Tejido en alcohol.

Cobitis paludica (de Buen, 1930)

MNCN/ADN: 10097 al 10100. Río Lozoya. Madrid. 18 de junio de 1991. Tejido en alcohol.

\section{Orden SALMONIFORMES}

\section{Familia SALMONIDAE}

Salmo trutta Linnaeus, 1758

MNCN/ADN: 3348, 3356. Parque Natural de Peñalara. Rascafría. Madrid. Marzo de 2003. Tejido congelado.

MNCN/ADN: 3530 al 3532. Arroyo Hoya de Pepe Hernando. Parque Natural de Peñalara. Rascafría. Madrid. 19 de junio de 2003. Tejido en alcohol.

MNCN/ADN: 3758 al 3788. Arroyo Hoya de Pepe Hernando. Parque Natural de Peñalara. Rascafría. Madrid. 27 de agosto de 2003. Tejido en alcohol.

MNCN/ADN: 6639 al 6688. Hoya de Pepe Hernando. Parque Natural de Peñalara. Rascafría. Madrid. 7 de septiembre de 2004. Tejido en alcohol. MNCN/ADN: 6689 al 6695. Hoya de Pepe Hernando. Parque Natural de Peñalara. Rascafría. Madrid. 23 de agosto de 2004. Tejido en alcohol.

Salvelinus fontinalis (Mitchill, 1814)

MNCN/ADN: 1704 al 1708. Parque Natural de Peñalara. Rascafría. Madrid. Agosto de 2003. Tejido en alcohol.

\section{AMPHIBIA}

\section{Orden CAUDATA}

Familia SALAMANDRIDAE

Pleurodeles waltl Michahelles, 1830

MNCN/ADN: 4191. Fuenlabrada. Madrid. Tejido congelado
Salamandra salamandra (Linnaeus, 1758)

MNCN/ADN: 3436. Charcas del Circo. Parque Natural de Peñalara. Rascafría. Madrid. 6 de noviembre de 2003. Tejido en alcohol.

MNCN/ADN: 3522. Charca de la Mariposa. Parque Natural de Peñalara. Rascafría. Madrid. 2 de junio de 2003. Tejido en alcohol

MNCN/ADN: 3523. Charca de la Mariposa. Parque Natural de Peñalara. Rascafría. Madrid. 18 de junio de 2003. Tejido en alcohol

MNCN/ADN: 3525, 3637. Laguna de Pájaros. Parque Natural de Peñalara. Rascafría. Madrid. 18 de junio de 2003. Tejido en alcohol

MNCN/ADN: 3641. Charca Hoya de Pepe Hernando. Parque Natural de Peñalara. Rascafría. Madrid. 29 de julio de 2003. Tejido en alcohol

MNCN/ADN: 3645. Laguna de Pájaros. Parque Natural de Peñalara. Rascafría. Madrid. 6 de agosto de 2003. Tejido en alcohol

MNCN/ADN: 3654. Charca Hoya de Pepe Hernando. Parque Natural de Peñalara. Rascafría. Madrid. 29 de julio de 2003.

MNCN/ADN: 3665. Laguna de Pájaros. Parque Natural de Peñalara. Rascafría. Madrid. 6 de agosto de 2003. Tejido en alcohol

MNCN/ADN: 3668, 3669. Laguna de Pájaros. Parque Natural de Peñalara. Rascafría. Madrid. 29 de julio de 2003. Tejido en alcohol

MNCN/ADN: 3670. Laguna de Pájaros. Parque Natural de Peñalara. Rascafría. Madrid. 31 de julio de 2003. Tejido en alcohol

MNCN/ADN: 3674. Laguna de Pájaros. Parque Natural de Peñalara. Rascafría. Madrid. 29 de julio de 2003. Tejido en alcohol

MNCN/ADN: 3675. Laguna de Pájaros. Parque Natural de Peñalara. Rascafría. Madrid. 25 de julio de 2003. Tejido en alcohol

MNCN/ADN: 8009. Miraflores de la Sierra. Madrid. 25 de julio de 2003. ADN.

Triturus alpestris (Laurenti, 1768)

MNCN/ADN: 3416 al 3435. Charcas del Pico. Parque Natural de Peñalara. Rascafría. Madrid. 27 de mayo de 2003. Tejido en alcohol.

MNCN/ADN: 3437 al 3440. Charcas del Pico. Parque Natural de Peñalara. Rascafría. Madrid. 2 de junio de 2003. Tejido en alcohol.

MNCN/ADN: 3447, 3452. Charcas de Miraflores. Parque Natural de Peñalara. Rascafría. Madrid. 4 de junio de 2003. Tejido en alcohol.

MNCN/ADN: 3454 al 3459, 3462, 3463. Charcas de la Rubia. Parque Natural de Peñalara. Rascafría. Madrid. 4 de junio de 2003. Tejido en alcohol.

MNCN/ADN: 3519. Charca de la Pistola. Parque Natural de Peñalara. Rascafría. Madrid. 10 de junio de 2003. Tejido en alcohol.

MNCN/ADN: 3521. Charcas de la Rubia. Parque Natural de Peñalara. Rascafría. Madrid. 10 de junio de 2003. Tejido en alcohol.

MNCN/ADN: 3527 al 3529. Charcas de la Rubia. Parque Natural de Peñalara. Rascafría. Madrid. 18 de junio de 2003. Tejido en alcohol.

Triturus marmoratus (Latreille, 1800)

MNCN/ADN: 3441. Charcas de la Rubia. Parque Natural de Peñalara. Rascafría. Madrid. 2 de junio de 2003. Tejido en alcohol.

MNCN/ADN: 3446. Charcas de Miraflores. Parque Natural de Peñalara. Rascafría. Madrid. 4 de junio de 2003. Tejido en alcohol.

MNCN/ADN: 3461. Charcas de la Rubia. Parque Natural de Peñalara. Rascafría. Madrid. 4 de junio de 2003. Tejido en alcohol.

MNCN/ADN: 3648. Charcas de la Rubia. Parque Natural de Peñalara. Rascafría. Madrid. 31 de julio de 2003. Tejido en alcohol.

MNCN/ADN: 3661. Charca Larga y de las Piedras. Parque Natural de Peñalara. Rascafría. Madrid. 31 de julio de 2003. Tejido en alcohol.

MNCN/ADN: 8652 al 8656, 8794 al 8800,8833 al 8837. El Berrueco. Madrid. Tejido congelado

Triturus pygmaeus (Wolterstorff, 1905)

MNCN/ADN: 4408 al 4414. Collado Mediano. Madrid. 6 de mayo de 2004. Tejido en alcohol

MNCN/ADN: 8657 al 8661. Villalba. Madrid. Tejido congelado

\section{Orden ANURA}

Familia HYLIDAE

Hyla arborea (Linnaeus, 1758)

MNCN/ADN: 3442 al 3451. Charcas de Miraflores. Parque Natural de Peñalara. Madrid. Rascafría. 4 de junio de 2003. Tejido en alcohol

MNCN/ADN: 3465. Charcas de la Rubia. Parque Natural de Peñalara. Madrid. Rascafría. 4 de junio de 2003. Tejido en alcohol

MNCN/ADN: 3518, 3520. Charca de la Pistola. Parque Natural de Peñalara. Madrid. Rascafría. 10 de junio de 2003. Tejido en alcohol 
MNCN/ADN: 11074 al 11076. El Berrueco. Madrid. 22 de abril de 1993. Tejido congelado

Familia BUFONIDAE

Bufo bufo (Linnaeus, 1758)

MNCN/ADN: 3524. Laguna de Pájaros. Parque Natural de Peñalara. Rascafría. Madrid. 18 de junio de 2003. Tejido en alcohol

MNCN/ADN: 3634. Camino del agua. Parque Natural de Peñalara. Rascafría. Madrid. 29 de julio de 2003. Tejido en alcohol

MNCN/ADN: 3646. Charca Larga y de las Piedras. Parque Natural de Peñalara. Rascafría. Madrid. 31 de julio de 2003. Tejido en alcohol

MNCN/ADN: 3655. Charca Hoya de Pepe Hernando. Parque Natural de Peñalara. Rascafría. Madrid. 6 de agosto de 2003. Tejido en alcohol

MNCN/ADN: 3656. Laguna de Pájaros. Parque Natural de Peñalara Rascafría. Madrid. 31 de julio de 2003. Tejido en alcohol

MNCN/ADN: 3660. Camino del Agua. Parque Natural de Peñalara. Rascafría. Madrid. 6 de agosto de 2003. Tejido en alcohol

MNCN/ADN: 3663. Charca Hoya de Peñalara. Parque Natural de Peñalara. Rascafría. Madrid. 6 de agosto de 2003. Tejido en alcohol

MNCN/ADN: 3664. Camino del agua. Parque Natural de Peñalara. Rascafría. Madrid. 29 de julio de 2003. Tejido en alcohol

MNCN/ADN: 3667. Laguna de Pájaros. Parque Natural de Peñalara. Rascafría. Madrid. 25 de julio de 2003. Tejido en alcohol

MNCN/ADN: 3671, 3672. Laguna de Pájaros. Parque Natural de Peñalara. Rascafría. Madrid. 29 de julio de 2003. Tejido en alcohol

MNCN/ADN: 8003. Valdemanco. Madrid. ADN.

Bufo calamita Laurenti, 1768

MNCN/ADN: 3631. Fuente Cubeiro. Parque Natural de Peñalara. Rascafría. Madrid. 6 de agosto de 2003. Tejido en alcohol

MNCN/ADN: 3636, 3642. Fuente Cubeiro. Parque Natural de Peñalara. Rascafría. Madrid. 6 de agosto de 2003. Tejido en alcohol

MNCN/ADN: 3639. Hoya de Peñalara. Parque Natural de Peñalara. Rascafría. Madrid. 6 de agosto de 2003. Tejido en alcohol

MNCN/ADN: 3649. Camino del Agua. Parque Natural de Peñalara. Rascafría. Madrid. 6 de agosto de 2003. Tejido en alcohol

MNCN/ADN: 3650. Laguna Chica. Parque Natural de Peñalara. Rascafría Madrid. 6 de agosto de 2003. Tejido en alcohol

MNCN/ADN: 3657. Hoya de Peñalara. Parque Natural de Peñalara. Rascafría. Madrid. 6 de agosto de 2003. Tejido en alcohol

MNCN/ADN: 3659, 3662. Camino del agua. Parque Natural de Peñalara. Rascafría. Madrid. 29 de julio de 2003. Tejido en alcohol

Familia RANIDAE

Rana iberica Boulenger, 1879

MNCN/ADN: 3633, 3647, 3658. Charcas de Miraflores. Parque Natural de Peñalara. Rascafría. Madrid. 29 de julio de 2003. Tejido en alcohol

MNCN/ADN: 3640, 3652, 3653, 3666. Charca Hoya de Pepe Hernando. Parque Natural de Peñalara. Rascafría. Madrid. 1 de agosto de 2003. Tejido en alcohol

MNCN/ADN: 5164 al 5171. Peñalara. Rascafría. Madrid. Tejido en alcohol

Rana perezi Seoane, 1885

MNCN/ADN: 3444. Charcas de Miraflores. Parque Natural de Peñalara. Rascafría. Madrid. 4 de junio de 2003. Tejido en alcohol

MNCN/ADN: 3453, 3460, 3464. Charcas de la Rubia. Parque Natural de Peñalara. Rascafría. Madrid. 4 de junio de 2003. Tejido en alcohol

MNCN/ADN: 3526. Charcas de la Rubia. Parque Natural de Peñalara Rascafría. Madrid. 18 de junio de 2003. Tejido en alcohol

MNCN/ADN: 3632, 3635. Charcas Hoya de Peñalara. Parque Natural de Peñalara. Rascafría. Madrid. 6 de agosto de 2003. Tejido en alcohol

MNCN/ADN: 3638. Laguna Chica. Parque Natural de Peñalara. Rascafría. Madrid. 5 de agosto de 2003. Tejido en alcohol

MNCN/ADN: 3643, 3644, 3676. Charca Hoya de Pepe Hernando. Parque Natural de Peñalara. Rascafría. Madrid. 21 de agosto de 2003. Tejido en alcohol

MNCN/ADN: 3651. Charca Hoya de Pepe Hernando. Parque Natural de Peñalara. Rascafría. Madrid. 6 de agosto de 2003. Tejido en alcohol

Familia DISCOGLOSSIDAE

Género Alytes Wagler, 1829

MNCN/ADN: 8360, 8363, 8365, 8370, 8375, 8376, 8379, 8380, 8390, 8392, 8632. Madrid. Tejido congelado
MNCN/ADN: 8409, 8425, 8428, 8447, 8507, 8528, 8529. Puerto Cotos. Madrid. Tejido congelado

MNCN/ADN: 8463, 8487. Laguna de Peñalara. Madrid. Tejido congelado

Alytes cisternasii Boscá, 1879

MNCN/ADN: 8557, 8626. Villanueva de la Cañada. Madrid. Tejido congelado

Alytes obstetricans (Laurenti, 1768)

MNCN/ADN: 3673. Laguna de Pájaros. Parque Natural de Peñalara. Rascafría. Madrid. 25 de julio de 2003. Tejido en alcohol

MNCN/ADN: 6902 al 6911. Parque Natural de Peñalara. Rascafría. Madrid. 18 de octubre de 2004. Tejido congelado

MNCN/ADN: 8555, 8558. Villanueva de la Cañada. Madrid. Tejido congelado

\section{REPTILIA}

\section{Orden SQUAMATA}

Familia COLUBRIDAE

Elaphe scalaris (Schinz, 1822)

MNCN/ADN: 6759. Madrid. 10 de septiembre de 2004. Tejido congelado.

MNCN/ADN: $\mathbf{6 8 1 7}, \mathbf{1 6 9 5 5}, \mathbf{1 7 8 7 7}$. Madrid. Tejido congelado.

MNCN/ADN: 17841. Collado Mediano. Madrid. 6 de junio de 2004. Tejido congelado.

Malpolon monspessulanus (Hermann, 1804)

MNCN/ADN: 720. Manjirón. Madrid. 25 de septiembre de 2002. Tejido congelado.

MNCN/ADN: 1716. Collado Mediano. Madrid. Mayo de 2003. Tejido liofilizado

MNCN/ADN: 3492. Puentes Viejas. Madrid. 28 de mayo de 2003. Tejido congelado.

MNCN/ADN: 7114. Móstoles. Madrid. 17 de septiembre de 2004. Tejido congelado.

Natrix maura (Linnaeus, 1758)

MNCN/ADN: 1515. Collado Villalba. Madrid. 3 de noviembre de 2002. Tejido congelado.

MNCN/ADN: 3480, 3481, 3482 . Móstoles. Madrid. 18 de mayo de 2003. Tejido congelado.

\section{Familia LACERTIDAE}

Lacerta lepida Daudin, 1802

MNCN/ADN: 7091. Pelayos de la Presa. Madrid. Tejido congelado.

MNCN/ADN: 7134. Navalcarnero. Madrid. Tejido congelado.

MNCN/ADN: 10147. Manzanares el Real. Madrid. Tejido congelado.

Lacerta schreiberi Bedriaga, 1878

MNCN/ADN: 6778. Rascafría. Madrid. Tejido congelado.

Psammodromus algirus (Linnaeus, 1758)

MNCN/ADN: 2106. Manjirón. Madrid. Tejido congelado.

Orden CHELONII

\section{Familia BATAGURIDAE}

Mauremys leprosa (Schweigger, 1812)

MNCN/ADN: 3496. Robledo de Chavela. Madrid. 31 de mayo de 2003. Tejido congelado.

MNCN/ADN: 6410. Madrid. Tejido congelado.

MNCN/ADN: 6774. Buitrago de Lozoya. Madrid. 01 de agosto de 2004 Tejido congelado.

MNCN/ADN: 17892. Madrid. Tejido congelado.

\section{AVES}

\section{Orden PODICIPEDIFORMES}

Familia PODICIPEDIDAE

Tachybaptus ruficollis (Pallas, 1764)

MNCN/ADN: 10396. Aluche. Madrid. 22 de junio de 2001. Tejido congelado, alcohol y liofilizado. 


\section{Orden PELECANIFORMES}

Familia PHALACROCORACIDAE

Phalacrocorax carbo (Linnaeus, 1758)

MNCN/ADN: 7109. San Martín de la Vega. Madrid. 22 de noviembre de 2004. Tejido congelado.

MNCN/ADN: 10347. Cercedilla. Madrid. 15 de diciembre de 2001. Tejido congelado y alcohol.

MNCN/ADN: 17943. San Martín de la Vega. Madrid. 22 de noviembre de 2005. Tejido congelado.

\section{Orden CICONIIFORMES}

Familia ARDEIDAE

Ardea cinerea Linnaeus, 1758

MNCN/ADN: 617. Villamanrique de Tajo. Madrid. 29 de julio de 2002. Tejido congelado.

MNCN/ADN: 2775. Navas del Rey. Madrid. 7 de enero de 2003. Tejido congelado.

MNCN/ADN: 7119. Alcalá de Henares. Madrid. 20 de septiembre de 2004. Tejido congelado.

MNCN/ADN: 7130, 7145. San Lorenzo del Escorial. Madrid. 18 de octubre de 2004. Tejido congelado.

MNCN/ADN: 10406. Madrid. Tejido congelado, alcohol y liofilizado.

Bubulcus ibis (Linnaeus, 1758)

MNCN/ADN: 663. San Sebastián de los Reyes. Madrid. 12 de agosto de 2002. Tejido congelado y alcohol.

MNCN/ADN: 703. Madrid. Tejido congelado.

MNCN/ADN: 704. Algete. Madrid. 6 de septiembre de 2002. Tejido congelado.

MNCN/ADN: 706. Algete. Madrid. 27 de agosto de 2002. Tejido congelado.

MNCN/ADN: 722. San Agustín de Guadalix. Madrid. 7 de octubre de 2002. Tejido congelado.

MNCN/ADN: 2351. Rivas-Vaciamadrid. Madrid. 26 de noviembre de 2002. Tejido congelado.

MNCN/ADN: 2767. Aranjuez. Madrid. 15 de diciembre de 002. Tejido congelado.

MNCN/ADN: 3611. Cienpozuelos. Madrid. 22 de julio de 2003. Tejido congelado, alcohol y liofilizado.

MNCN/ADN: 3684. Fuente el Saz del Jarama. Madrid. 18 de agosto de 2003. Tejido congelado y alcohol.

MNCN/ADN: 3878. San Agustín de Guadalix. Madrid. 26 de agosto de 2003. Tejido congelado.

MNCN/ADN: 3879. San Agustín de Guadalix. Madrid. 28 de agosto de 2003. Tejido congelado.

MNCN/ADN: 6790. San Fernando de Henares. Madrid. 19 de agosto de 2004. Tejido congelado.

MNCN/ADN: 7085. Patones. Madrid. 04 de diciembre de 2004. Tejido congelado.

MNCN/ADN: 10368. Torrejón de Ardoz. Madrid. Tejido congelado y alcohol.

MNCN/ADN: 10469. Algete. Madrid. 10 de agosto de 2000. Tejido congelado. Tejido congelado y alcohol.

MNCN/ADN: 10475. Alcobendas. Madrid. 14 de agosto de 2003. Tejido congelado. Tejido congelado y liofilizado.

MNCN/ADN: 10934. Madrid. Tejido congelado. Liofilizado.

MNCN/ADN: 10957. Madrid. Tejido congelado. Liofilizado.

MNCN/ADN: 17872. San Agustín de Guadalix. Madrid. 1 de agosto de 2005. Tejido congelado.

MNCN/ADN: 17913. Torrejón de Velasco. Madrid. 22 de junio de 2005. Tejido congelado.

Ixobrychus minutus (Linnaeus, 1766)

MNCN/ADN: 710. Rivas-Vaciamadrid. Madrid. 30 de agosto de 2002. Tejido congelado.

Nycticorax nycticorax (Linnaeus, 1758)

MNCN/ADN: 670. San Fernando de Henares. Madrid. 14 de agosto de 2002. Tejido congelado, alcohol y liofilizado.

Familia CICONIIDAE

Ciconia ciconia (Linnaeus, 1758)

MNCN/ADN: 604, 605. Manzanares el Real. Madrid. 6 de agosto de 2002. Tejido congelado.
MNCN/ADN: 606. Garganta de los Montes. Madrid. 6 de agosto de 2002. Tejido congelado.

MNCN/ADN: 607. Paracuellos del Jarama. Madrid. 6 de agosto de 2002. Tejido congelado.

MNCN/ADN: 608. Manzanares del Real. Madrid. 6 de agosto de 2002. Tejido congelado.

MNCN/ADN: 637. Mejorada del Campo. Madrid. 8 de agosto de 2002. Tejido congelado.

MNCN/ADN: 2760. Manzanares el Real. Madrid. 3 de febrero de 2003. Tejido congelado.

MNCN/ADN: 2784. La Serna del Monte. Madrid. 18 de enero de 2003. Tejido congelado.

MNCN/ADN: 2798. Lozoya. Madrid. 28 de enero de 2003. Tejido congelado. MNCN/ADN: 2800. Rivas-Vaciamadrid. Madrid. 29 de enero de 2003. Tejido congelado.

MNCN/ADN: 2801. Rivas-Vaciamadrid. Madrid. 19 de enero de 2003. Tejido congelado.

MNCN/ADN: 3194. Lozoya. Madrid. 10 de marzo de 2003. Tejido congelado.

MNCN/ADN: 3198. Soto del Real. Madrid. 9 de febrero de 2003. Tejido congelado.

MNCN/ADN: 3202. Soto del Real. Madrid. 14 de febrero de 2003. Tejido congelado.

MNCN/ADN: 3206. Pinilla del Valle. Madrid. 6 de marzo de 2003. Tejido congelado.

MNCN/ADN: 3209. Manzanares el Real. Madrid. 10 de marzo de 2003. Tejido congelado.

MNCN/ADN: 3358. Guadalix de la Sierra. Madrid. 26 de marzo de 2003. Tejido congelado.

MNCN/ADN: 3368. Guadarrama. Madrid. 14 de abril de 2003. Tejido congelado.

MNCN/ADN: 3374. San Martín de Valdeiglesias. Madrid. 21 de abril de 2003. Tejido congelado y ADN.

MNCN/ADN: 3376. San Martín de la Vega. Madrid. 8 de abril de 2003. Tejido congelado.

MNCN/ADN: 3378. Tres Cantos. Madrid. 5 de mayo de 2003. Tejido congelado.

MNCN/ADN: 3381. Colmenar Viejo. Madrid. 5 de mayo de 2003. Tejido congelado.

MNCN/ADN: 3382 al 3395. Guadarrama. Madrid. 7 de abril de 2003. Tejido congelado.

MNCN/ADN: 3397. San Fernando de Henares. Madrid. 21 de abril de 2003. Tejido congelado.

MNCN/ADN: 3466. Lozoya. Madrid. 7 de mayo de 2003. Tejido congelado, alcohol y liofilizado. Tejido congelado.

MNCN/ADN: 3477. Cerceda. Madrid. 17 de mayo de 2003. Tejido congelado.

MNCN/ADN: 3478. Manzanares el Real. Madrid. 17 de mayo de 2003. Tejido congelado.

MNCN/ADN: 3485. San Martín de la Vega. Madrid. 21 de mayo de 2003. Tejido congelado, alcohol y liofilizado.

MNCN/ADN: 3510. Tres Cantos. Madrid. 9 de mayo de 2003. Tejido congelado.

MNCN/ADN: 3549. Manzanares el Real. Madrid. 11 de junio de 2003. Tejido congelado.

MNCN/ADN: 3564. Manzanares el Real. Madrid. 15 de julio de 2003. Tejido congelado.

MNCN/ADN: 3565. Torrelaguna. Madrid. 15 de julio de 2003. Tejido congelado.

MNCN/ADN: 3571. Móstoles. Madrid. 15 de julio de 2003. Tejido congelado.

MNCN/ADN: 3572. La Cabrera. Madrid. 21 de julio de 2003. Tejido congelado.

MNCN/ADN: 3575. El Escorial. Madrid. 21 de julio de 2003. Tejido congelado.

MNCN/ADN: 3576. Galapagar. Madrid. 21 de julio de 2003. Tejido congelado.

MNCN/ADN: 3577. El Boalo. Madrid. 15 de julio de 2003. Tejido congelado.

MNCN/ADN: 3580. Manzanares el Real. Madrid. 21 de julio de 2003. Tejido congelado.

MNCN/ADN: 3584. Soto del Real. Madrid. 15 de julio de 2003. Tejido congelado.

MNCN/ADN: 3585. Soto del Real. Madrid. 21 de julio de 2003. Tejido congelado.

MNCN/ADN: 3587. Alcalá de Henares. Madrid. 11 de julio de 2003. Tejido congelado. 
MNCN/ADN: 3590. Soto del Real. Madrid. 21 de julio de 2003. Tejido congelado.

MNCN/ADN: 3591. Cercedilla. Madrid. 21 de julio de 2003. Tejido congelado.

MNCN/ADN: 3608. Soto del Real. Madrid. 17 de julio de 2003. Tejido congelado.

MNCN/ADN: 3609. Parla. Madrid. 19 de julio de 2003. Tejido congelado.

MNCN/ADN: 3618. Soto del Real. Madrid. 25 de julio de 2003. Tejido congelado.

MNCN/ADN: 3623. San Martín de la Vega. Madrid. 28 de julio de 2003. Tejido congelado.

MNCN/ADN: 6424. Manzanares el Real. Madrid. 19 de abril de 2004 Tejido congelado.

MNCN/ADN: 6430. Soto del Real. Madrid. 1 de julio de 2004. Tejido congelado.

MNCN/ADN: 6442. Alcalá de Henares. Madrid. 20 de junio de 2004 Tejido congelado.

MNCN/ADN: 6446. Manzanares El Real. Madrid. 18 de junio de 2004 Tejido congelado.

MNCN/ADN: 6459. Pinilla del Valle. Madrid. 6 de julio de 2004. Tejido congelado.

MNCN/ADN: 6712. Lozoyuela. Madrid. 4 de agosto de 2004. Tejido congelado.

MNCN/ADN: 6760. Alcalá de Henares. Madrid. 30 de agosto de 2004. Tejido congelado.

MNCN/ADN: 6761. Alcalá de Henares. Madrid. 4 de agosto de 2004. Tejido congelado.

MNCN/ADN: 6764. Perales del Río. Madrid. 26 de julio de 2004. Tejido congelado.

MNCN/ADN: 6776. Alcalá de Henares. Madrid. 10 de agosto de 2004 Tejido congelado.

MNCN/ADN: 6800. Soto del Real. Madrid. 25 de agosto de 2004. Tejido congelado.

MNCN/ADN: 6803. Loeches. Madrid. 31 de agosto de 2004. Tejido congelado. MNCN/ADN: 10137. Peralejo. Madrid. 25 de junio de 2002. Tejido congelado MNCN/ADN: 10139, 10159. Manzanares del Real. Madrid. 16 de julio de 2002. Tejido congelado.

MNCN/ADN: 10162. San Martín de la Vega. Madrid. 16 de julio de 2002. Tejido congelado.

MNCN/ADN: 10163. Soto del Real. Madrid. 16 de julio de 2002. Tejido congelado.

MNCN/ADN: 10164 al 10168. Madrid. 16 de julio de 2002. Tejido congelado. MNCN/ADN: 10178. Guadalix de la Sierra. Madrid. 22 de julio de 2002. Tejido congelado.

MNCN/ADN: 10179. Barajas. Madrid. 22 de julio de 2002. Tejido congelado. MNCN/ADN: 10191, 10192. Madrid. 04 de julio de 2002. Tejido congelado.

MNCN/ADN: 10194. Soto del Real. Madrid. 10 de julio de 2002. Tejido congelado.

MNCN/ADN: 10386. Pinto. Madrid. 29 de julio de 2001. Tejido congelado, alcohol y liofilizados.

MNCN/ADN: 10418. Chapinería. Madrid. 10 de junio de 2003. Tejido congelado, alcohol y liofilizados.

MNCN/ADN: 17849. Alcalá de Henares. Madrid. 20 de junio de 2005. Tejido congelado.

MNCN/ADN: 17861. Alcalá de Henares. Madrid. 17 de agosto de 2005 Tejido congelado.

Ciconia nigra (Linnaeus, 1758)

MNCN/ADN: 3399. Madrid. 19 de junio de 2002. Tejido congelado y ADN MNCN/ADN: 3400. Madrid. 17 de junio de 2002. Tejido congelado y ADN MNCN/ADN: 3401 al 3403. Madrid. Tejido congelado y ADN.

MNCN/ADN: 3404. Madrid. 24 de junio de 2002. Tejido congelado y ADN. MNCN/ADN: 3405. Madrid. Tejido congelado y ADN.

MNCN/ADN: 3701. Madrid 2003. Tejido liofilizado.

MNCN/ADN: 4326. Madrid. 17 de junio de 2002. Tejido congelado.

MNCN/ADN: 10492. San Agustín de Guadalix. Madrid. 3 de mayo de 2000. Tejido congelado, alcohol y liofilizado.

\section{Orden ANSERIFORMES}

Familia ANATIDAE

Anas crecca Linnaeus, 1758

MNCN/ADN: 4190. Aravaca. Madrid. 12 de noviembre de 2003. Tejido congelado
Anas platyrhynchos Linnaeus, 1758

MNCN/ADN: 2366. Madrid. Tejido congelado.

MNCN/ADN: 2786 al 2791. Fuentidueña de Tajo. Madrid. 19 de enero de 2003. Tejido congelado.

MNCN/ADN: 3479. Rivas-Vaciamadrid. Madrid. 17 de mayo de 2003. Tejido congelado.

MNCN/ADN: 3483. Perales del Río. Madrid. 20 de mayo de 2003. Tejido congelado.

MNCN/ADN: 6425, 6426. Madrid. 8 de julio de 2004. Tejido congelado.

MNCN/ADN: 6710. Colmenar Viejo. Madrid. 30 de agosto de 2004. Tejido congelado.

MNCN/ADN: 6752 al 6754. Madrid. 9 de septiembre de 2004. Tejido congelado.

MNCN/ADN: 7110 al 7112. Madrid. Tejido congelado.

MNCN/ADN: 7113. Móstoles. Madrid. 17 de septiembre de 2004. Tejido congelado.

MNCN/ADN: 10141. Madrid. 16 de julio de 2002. Tejido congelado.

MNCN/ADN: 10155. Alcorcón. Madrid. 16 de julio de 2002. Tejido congelado.

MNCN/ADN: 17917. Aravaca. Madrid. 3 de agosto de 2005. Tejido congelado

MNCN/ADN: 17927. Torrejón de Velasco. Madrid. 15 de noviembre de 2001. Tejido congelado.

MNCN/ADN: 17929. Aranjuez. Madrid. 16 de diciembre de 2001. Tejido congelado.

\section{Orden FALCONIFORMES}

\section{Familia ACCIPITRIDAE}

Accipiter gentilis (Linnaeus, 1758)

MNCN/ADN: 675. Algete. Madrid. 16 de agosto de 2002. Tejido congelado, alcohol y liofilizado.

MNCN/ADN: 676. Algete. Madrid. 16 de agosto de 2002. Tejido congelado.

MNCN/ADN: 705. Algete. Madrid. 30 de septiembre de 2002. Tejido congelado.

MNCN/ADN: 716. San Fernando de Henares. Madrid. 14 de septiembre de 2002. Tejido congelado.

MNCN/ADN: 726. Guadalix de la Sierra. Madrid. 8 de octubre de 2002. Tejido congelado.

MNCN/ADN: 2761. Torrelodones. Madrid. 2 de febrero de 2003. Tejido congelado.

MNCN/ADN: 2785. Navalagamella. Madrid. 18 de enero de 2003. Tejido congelado.

MNCN/ADN: 3215. Villaviciosa de Odón. Madrid. 17 de marzo de 2003. Tejido congelado.

MNCN/ADN: 3837. Arganda. Madrid. 8 de agosto de 2003. Tejido congelado.

MNCN/ADN: 6438. Villar del Olmo. Madrid. 11 de junio de 2004. Tejido congelado.

MNCN/ADN: 6439. Fresnedillas de la Oliva. Madrid. 11 de junio de 2004. Tejido congelado.

MNCN/ADN: 10158. Montejo de la Sierra. Madrid. 15 de julio de 2002. Tejido congelado.

MNCN/ADN: 10352. Madrid. Tejido congelado y alcohol.

MNCN/ADN: 10389. Lozoya. Madrid. 7 de septiembre de 2001. Tejido congelado y alcohol.

MNCN/ADN: 10702. Serracines. Madrid. 11 de enero de 2001. Tejido congelado y liofilizado.

MNCN/ADN: 10712. Aldea del Fresno. Madrid. 27 de octubre de 2000. Tejido congelado y liofilizado.

MNCN/ADN: 10719. Villanueva de Perales. Madrid. 30 de octubre de 2000. Tejido congelado.

MNCN/ADN: 10735. Madrid. 1 de febrero de 1999. Tejido congelado y liofilizado.

MNCN/ADN: 10736. Valdaracete. Madrid. 29 de julio de 2001. Tejido congelado y liofilizado.

MNCN/ADN: 10861, 10884. Madrid. Tejido liofilizado.

MNCN/ADN: 17938. Valdemorillo. Madrid. 09 de enero de 2002. Tejido congelado.

Accipiter nisus (Linnaeus, 1758)

MNCN/ADN: 712. Patones. Madrid. 9 de septiembre de 2002. Tejido congelado.

MNCN/ADN: 1513. Chapineria. Madrid. 14 de octubre de 2002. Tejido congelado. 
MNCN/ADN: 1521. Madrid. 27 de octubre de 2002. Tejido congelado.

MNCN/ADN: 2364. Torremocha del Jarama. Madrid. 26 de noviembre de 2002. Tejido congelado y liofilizado.

MNCN/ADN: 2766. Pelayos de la Presa. Madrid. 11 de diciembre de 2002. Tejido congelado.

MNCN/ADN: 2774, 2776. Madrid. 7 de enero de 2003. Tejido congelado.

MNCN/ADN: 2781. El Álamo. Madrid. 13 de enero de 2003. Tejido congelado.

MNCN/ADN: 2796. Torres de la Alameda. Madrid. 25 de enero de 2003. Tejido congelado.

MNCN/ADN: 3365. Rascafría. Madrid. 7 de abril de 2003. Tejido congelado

MNCN/ADN: 3838. Manjirón. Madrid. 17 de octubre de 2003. Tejido congelado.

MNCN/ADN: 3880. Cercedilla. Madrid. 2003. Tejido congelado.

MNCN/ADN: 4189, 4214. Chinchón. Madrid. 20 de noviembre de 2003. Tejido congelado.

MNCN/ADN: 6453. Aldea del Freno. Madrid. 22 de junio de 2004. Tejido congelado.

MNCN/ADN: 7101. Brunete. Madrid. 3 de noviembre de 2004. Tejido congelado.

MNCN/ADN: 7141. La Serna del Monte. Madrid. 12 de octubre de 2004 Tejido congelado.

MNCN/ADN: 7147. Becerril de la Sierra. Madrid. 04 de diciembre de 2004. Tejido congelado.

MNCN/ADN: 7148. Camarma de Esteruelas. Madrid. 15 de octubre de 2004. Tejido congelado.

MNCN/ADN: 10707. Venturada. Madrid. 23 de mayo de 2002. Tejido congelado y liofilizado.

MNCN/ADN: 10737. Madrid. Tejido congelado y liofilizado.

MNCN/ADN: $10851,10852,10878$ al 10880 y 10883. Madrid. Tejido liofilizado.

Aegypius monachus (Linnaeus, 1766)

MNCN/ADN: 1511. Garganta de los Montes. Madrid. 4 de noviembre de 2002. Tejido congelado.

MNCN/ADN: 2419. Aranjuez. Madrid. 12 de noviembre de 2002. Tejido liofilizado.

MNCN/ADN: 3468. Ajalvir. Madrid. 26 de mayo de 2003. Tejido congelado.

MNCN/ADN: 6429. Rascafría. Madrid. 29 de junio de 2004. Tejido congelado.

MNCN/ADN: 6808. Rascafría. Madrid. 9 de septiembre de 2004. Tejido congelado.

MNCN/ADN: 6810. Camarma. Madrid. 10 de septiembre de 2004. Tejido congelado.

MNCN/ADN: 7106. Madrid. 12 de diciembre de 2004. Tejido congelado.

MNCN/ADN: 10328. Rascafría. Madrid. Julio de 1998. Tejido liofilizado.

MNCN/ADN: 17855, 17873, 17887. Madrid. Tejido congelado.

Aquila adalberti Brehm, 1861

MNCN/ADN: 2354. Madrid. Tejido congelado.

MNCN/ADN: 3567, 3568. Cadalso de los Vidrios. Madrid. 22 de junio de 2003. Tejido congelado.

MNCN/ADN: 3578. Madrid. 1 de julio de 2003. Tejido congelado.

MNCN/ADN: 3685. Soto del Real. Madrid. 18 de agosto de 2003. Tejido congelado.

MNCN/ADN: 4246. El Salobral. Chapinería. Madrid. 24 de octubre de 1991. Tejido alcohol.

MNCN/ADN: 7143. Guadalix de la Sierra. Madrid. 08 de noviembre de 2004. Tejido congelado.

MNCN/ADN: 10138. Madrid. 22 de junio de 2002. Tejido congelado.

MNCN/ADN: 10877. Aldea del Fresno. Madrid. Tejido liofilizado.

MNCN/ADN: 10888, 10898. Madrid. Tejido liofilizado.

Aquila chrysaetos (Linnaeus, 1758)

MNCN/ADN: 10185. San Fernando de Henares. Madrid. 23 de julio de 2002. Tejido congelado.

MNCN/ADN: 10374, 10375. Arganda. Madrid. Tejido liofilizado.

MNCN/ADN: 10375. Arganda. Madrid. Tejido congelado

MNCN/ADN: 10750, 10876. Madrid. Tejido liofilizado.

Buteo buteo (Linnaeus, 1758)

MNCN/ADN: 624. Alde a del Fresno. Madrid. 1 de agosto de 2002. Tejido congelado.
MNCN/ADN: 654. Madrid. 13 de agosto de 2002. Tejido congelado.

MNCN/ADN: 668. Chapinería. Madrid. 12 de agosto de 2002. Tejido congelado.

MNCN/ADN: 702. Madrid. Tejido congelado y alcohol.

MNCN/ADN: 708. Navalcarnero. Madrid. 9 de septiembre de 2002. Tejido congelado.

MNCN/ADN: 713. Madrid. 30 de septiembre de 2002. Tejido congelado y liofilizado.

MNCN/ADN: 714. San Martín de Valdeiglesias. Madrid. 20 de septiembre de 2002. Tejido congelado.

MNCN/ADN: 719. Aranjuez. Madrid. 19 de septiembre de 2002. Tejido congelado.

MNCN/ADN: 728. Buitrago de Lozoya. Madrid. 10 de octubre de 2002. Tejido congelado.

MNCN/ADN: 1512. Fuentidueña de Tajo. Madrid. 23 de octubre de 2002. Tejido congelado.

MNCN/ADN: 2355. Leganés. Madrid. 13 de noviembre de 2002. Tejido congelado.

MNCN/ADN: 2356. Tres Cantos. Madrid. 8 de noviembre de 2002. Tejido congelado.

MNCN/ADN: 2365. Villanueva de la Cañada. Madrid. 17 de noviembre de 2002. Tejido congelado.

MNCN/ADN: 2372. Rascafría. Madrid. 6 de diciembre de 2002. Tejido congelado y liofilizado.

MNCN/ADN: 2769. Moraleja de Enmedio. Madrid. 19 de diciembre de 2002. Tejido congelado.

MNCN/ADN: 2773. Alcobendas. Madrid. 26 de octubre de 2002. Tejido congelado.

MNCN/ADN: 2780. San Martín de Valdeiglesias. Madrid. 13 de enero de 2003. Tejido congelado.

MNCN/ADN: 2799. Robledo de Chavela. Madrid. 4 de febrero de 2003. Tejido congelado.

MNCN/ADN: 2803. Navalcarnero. Madrid. 3 de febrero de 2003. Tejido congelado.

MNCN/ADN: 3193. Aranjuez. Madrid. 18 de marzo de 2003. Tejido congelado.

MNCN/ADN: 3197. Alameda del Valle. Madrid. 8 de febrero de 2003. Tejido congelado.

MNCN/ADN: 3512. Madrid. 10 de marzo de 2003. Tejido congelado, alcohol y liofilizado.

MNCN/ADN: 3544. Valdemanco. Madrid. 6 de junio de 2003. Tejido congelado.

MNCN/ADN: 3554. El Cuadrón. Madrid. 18 de junio de 2003. Tejido congelado, alcohol y liofilizado.

MNCN/ADN: 4198. Pinilla del Valle. Madrid. 22 de noviembre de 2003. Tejido congelado.

MNCN/ADN: 4201. Becerril de la Sierra. Madrid. 15 de diciembre de 2003. Tejido congelado.

MNCN/ADN: 6423. Belvis de Jarama. Madrid. 9 de junio de 2004. Tejido congelado.

MNCN/ADN: 6716. Colmenar Viejo. Madrid. 29 de julio de 2004. Tejido congelado.

MNCN/ADN: 6768. Miraflores de la Sierra. Madrid. 27 de julio de 2004. Tejido congelado.

MNCN/ADN: 7095. Villamanta. Madrid. 25 de septiembre de 2004. Tejido congelado.

MNCN/ADN: 7140. Madrid. 11 de octubre de 2004. Tejido congelado.

MNCN/ADN: 7142. San Martín de la Vega. Madrid. 01 de diciembre de 2004. Tejido congelado.

MNCN/ADN: 10157. Buitrago de Lozoya. Madrid. 15 de julio de 2002. Tejido congelado.

MNCN/ADN: 10180. Valdelatas/Canto Blanco. Madrid. 22 de julio de 2002. Tejido congelado.

MNCN/ADN: 10183. Canencia. Madrid. 17 de julio de 2002. Tejido congelado.

MNCN/ADN: 10264. Villa del Prado. Madrid. 16 de mayo de 2002. Tejido liofilizado.

MNCN/ADN: 10371. Guadarrama. Madrid. 8 de mayo de 2003. Tejido congelado, alcohol y liofilizado.

MNCN/ADN: 10424. Robledo de Chavela. Madrid. 8 de julio de 2003. Tejido liofilizado.

MNCN/ADN: 10436. Campo Real. Madrid. 3 de julio de 2003. Tejido congelado, alcohol y liofilizado. 
MNCN/ADN: 10480. San Martín de Valdeiglesias. Madrid. 30 de enero de 2001. Tejido congelado, alcohol y liofilizado.

MNCN/ADN: 10669. Estremera. Madrid. 2 de noviembre de 1990. Tejido congelado y liofilizado.

MNCN/ADN: 10703. Valdaracete. Madrid. 19 de enero de 2001. Tejido congelado y liofilizado.

MNCN/ADN: 10727. Valdaracete. Madrid. 26 de junio de 2000. Tejido congelado.

MNCN/ADN: 10728. San Lorenzo del Escorial. Madrid. 16 de agosto de 2000. Tejido congelado.

MNCN/ADN: 10729. Buitrago de Lozoya. Madrid. 17 de julio de 2001 Tejido congelado y liofilizado.

MNCN/ADN: 10749. Colmenar de Oreja. Madrid. 7 de agosto de 2001. Tejido congelado y liofilizado.

MNCN/ADN: 10854, 10872 al 10874, 10922, 10959. Madrid. Tejido liofilizado.

MNCN/ADN: $\mathbf{1 7 8 5 7 ,} \mathbf{1 7 8 6 9}, \mathbf{1 7 8 8 2}, \mathbf{1 7 8 9 1}$. Madrid. Tejido congelado.

MNCN/ADN: 17907. Villamanta. Madrid. 25 de septiembre de 2004. Tejido congelado.

Circaetus gallicus (Gmelin, 1788)

MNCN/ADN: 2357. Chapineria. Madrid. 10 de noviembre de 2002. Tejido congelado.

MNCN/ADN: 3621. Aranjuez. Madrid. 28 de julio de 2003. Tejido congelado y alcohol.

MNCN/ADN: 3873. Peralejo. Madrid. 28 de agosto de 2003. Tejido congelado.

MNCN/ADN: 10437. Coto de caza Camino del Pasajo. Madrid. 18 de agosto de 2003. Tejido liofilizado.

MNCN/ADN: 10462. Manjirón. Madrid. 13 de agosto de 2000. Tejido congelado y alcohol.

MNCN/ADN: 10662. Gascones. Madrid. 17 de abril de 2003. Tejido liofilizado.

MNCN/ADN: 10717. Villamanrique de Tajo. Madrid. 17 de julio de 2001 Tejido congelado, alcohol y liofilizado.

Circus aeruginosus (Linnaeus, 1758)

MNCN/ADN: 3872. Daganzo. Madrid. 28 de agosto de 2003. Tejido congelado

MNCN/ADN: 6461. Camarma de Esteruelas. Madrid. 09 de julio de 2004. Tejido congelado.

MNCN/ADN: 10490. San Martín de la Vega. Madrid. 14 de diciembre de 2002. Tejido congelado, alcohol y lifilizado.

MNCN/ADN: 10864. Madrid. Tejido lifilizado.

Circus pygargus (Linnaeus, 1758)

MNCN/ADN: 600. Ajalvir. Madrid. 1 de agosto de 2002. Tejido congelado

MNCN/ADN: 3476. Torrelaguna. Madrid. 16 de mayo de 2003. Tejido congelado.

MNCN/ADN: 10203. Daganzo. Madrid. 16 de abril de 2002. Tejido congelado.

MNCN/ADN: 10308. Colmenar de Oreja. Madrid. 7 de julio de 2001 Tejido congelado y alcohol.

MNCN/ADN: 10423. San Martín de la Vega. Madrid. 23 de julio de 2003. Tejido liofilizado.

MNCN/ADN: 10867, 10935, 10958. Madrid. Tejido liofilizado.

Gyps fulvus (Hablizl, 1783)

MNCN/ADN: 626. Manzanares el Real. Madrid. 2 de agosto de 2002 Tejido congelado.

MNCN/ADN: 660. Chinchón. Madrid. 12 de agosto de 2002. Tejido congelado.

MNCN/ADN: 709. Parla. Madrid. 24 de septiembre de 2002. Tejido congelado.

MNCN/ADN: 711. La Cabrera. Madrid. 31 de agosto de 2002. Tejido congelado.

MNCN/ADN: 715. El Berrueco. Madrid. 24 de septiembre de 2002. Tejido congelado.

MNCN/ADN: 721, 2367, 7094, 17884. Madrid. Tejido congelado.

MNCN/ADN: 723. Alcorcón. Madrid. 7 de octubre de 2002. Tejido congelado.

MNCN/ADN: 1514. La Cabrera. Madrid. 14 de octubre de 2002. Tejido congelado.

MNCN/ADN: 1516. El Berrueco. Madrid. 24 de octubre de 2002. Tejido congelado.
MNCN/ADN: 1517. Alcorcón. Madrid. 24 de octubre de 2002. Tejido congelado.

MNCN/ADN: 1519. Alcobendas. Madrid. 24 de octubre de 2002. Tejido congelado.

MNCN/ADN: 1527. Colmenar de Oreja. Madrid. 25 de noviembre de 2002. Tejido congelado.

MNCN/ADN: 1537. Madrid. 4 de noviembre de 2002. Tejido congelado.

MNCN/ADN: 2802. Pelayos de la Presa. Madrid. 30 de enero de 2003. Tejido congelado.

MNCN/ADN: 3619. La Cabrera. Madrid. 28 de julio de 2003. Tejido congelado.

MNCN/ADN: 3864. Guadalix de la Sierra. Madrid. 29 de agosto de 2003. Tejido congelado.

MNCN/ADN: 3865. La Cabrera. Madrid. 29 de agosto de 2003. Tejido congelado.

MNCN/ADN: 3866. San Martín de Valdeiglesias. Madrid. 29 de agosto de 2003. Tejido congelado.

MNCN/ADN: 3867. San Fernando de Henares. Madrid. 29 de agosto de 2003. Tejido congelado.

MNCN/ADN: 3868. Somosierra. Madrid. 7 de octubre de 2003. Tejido congelado.

MNCN/ADN: 3869. Carabaña. Madrid. 7 de octubre de 2003. Tejido congelado.

MNCN/ADN: 4202. Aranjuez. Madrid. 30 de octubre de 2003. Tejido congelado.

MNCN/ADN: 6458. Tres Cantos. Madrid. 03 de julio de 2004. Tejido congelado

MNCN/ADN: 6813. Manzanares el Real. Madrid. 12 de septiembre de 2004. Tejido congelado.

MNCN/ADN: 7099. Madrid. 2004. Tejido congelado.

MNCN/ADN: 7100. Coslada. Madrid. 14 de diciembre de 2004. Tejido congelado.

MNCN/ADN: 10653. Madrid. 23 de noviembre de 1999. Tejido congelado, alcohol y liofilizado.

MNCN/ADN: 10666. Somosierra. Madrid. 29 de junio de 2001. Tejido alcohol y liofilizado.

MNCN/ADN: 10667. Madrid. Tejido congelado y liofilizado.

Hieraaetus pennatus (Gmelin, 1788)

MNCN/ADN: 622. El Boalo. Madrid. 31 de julio de 2002. Tejido congelado.

MNCN/ADN: 629. Valdemorillo. Madrid. 3 de agosto de 2002. Tejido congelado.

MNCN/ADN: 678. Arganda del Rey. Madrid. 19 de agosto de 2002. Tejido congelado.

MNCN/ADN: 3581. Tres Cantos. Madrid. 7 de julio de 2003. Tejido congelado y liofilizado.

MNCN/ADN: 3614. Torrejón de Ardoz. Madrid. 24 de julio de 2003. Tejido congelado.

MNCN/ADN: 3617. Soto del Real. Madrid. 25 de julio de 2003. Tejido congelado.

MNCN/ADN: 6765. Mataelpino. Madrid. 27 de julio de 2004. Tejido congelado.

MNCN/ADN: 6782. Fuenlabrada. Madrid. 09 de agosto de 2004. Tejido congelado.

MNCN/ADN: 7118. Torrejón de la Calzada. Madrid. 16 de septiembre de 2004. Tejido congelado.

MNCN/ADN: 10213. Valdetorres de Jarama. Madrid. 12 de julio de 2002. Tejido congelado.

MNCN/ADN: 10379. Rascafría. Madrid. 1 de mayo de 2002. Tejido congelado y alcohol.

MNCN/ADN: 10390. Piñuecar. Madrid. 12 de septiembre de 2001. Tejido liofilizado.

MNCN/ADN: 10431. Valdemorillo. Madrid. 6 de mayo de 2002. Tejido congelado y alcohol.

MNCN/ADN: 10432. Madrid. 13 de junio de 2002. Tejido congelado y alcohol.

MNCN/ADN: 10438. Santa María de la Alameda. Madrid. 10 de agosto de 2003. Tejido congelado, alcohol y liofilizado.

MNCN/ADN: 10443. Buitrago de Lozoya. Madrid. 20 de junio de 2003. Tejido congelado, alcohol y liofilizado.

MNCN/ADN: 10711. Cubas de la Sagra. Madrid. 26 de septiembre de 2000. Tejido congelado y liofilizado.

MNCN/ADN: 10752. Madrid. Tejido congelado y liofilizado. 
MNCN/ADN: 10869, 10870, 10921. Madrid. Tejido liofilizado. MNCN/ADN: $\mathbf{1 7 8 6 5}, \mathbf{1 7 8 7 0}, \mathbf{1 7 8 8 3}$. Madrid. Tejido congelado. MNCN/ADN: 17939. Torrejón de la Calzada. Madrid. 16 de septiembre de 2004. Tejido congelado.

Milvus migrans (Boddaert, 1783)

MNCN/ADN: 653. Valdemoro. Madrid. 22 de agosto de 2002. Tejido congelado.

MNCN/ADN: 701, 10753, 10754. Madrid. Tejido congelado.

MNCN/ADN: 3546. Collado Villalba. Madrid. 9 de junio de 2003. Tejido congelado.

MNCN/ADN: 3875. Torrejón de Ardoz. Madrid. 24 de agosto de 2003. Tejido congelado.

MNCN/ADN: 6434. Buitrago de Lozoya. Madrid. 13 de julio de 2004 Tejido congelado.

MNCN/ADN: 6452. Aldea del Freno. Madrid. 22 de junio de 2004. Tejido congelado.

MNCN/ADN: 6715. Móstoles. Madrid. 29 de julio de 2004. Tejido congelado. MNCN/ADN: 6805. Rivas-Vaciamadrid. Madrid. 03 de septiembre de 2004. Tejido congelado.

MNCN/ADN: 10410. San Fernando de Henares. Madrid. 23 de julio de 2003. Tejido congelado, alcohol y liofilizado.

MNCN/ADN: 10430. Villavieja de Lozoya. Madrid. 16 de junio de 2002. Tejido congelado y alcohol.

MNCN/ADN: 10488. Pinto. Madrid. 19 de mayo de 2001. Tejido congelado, alcohol y liofilizado.

MNCN/ADN: 10489. Madrid. 9 de julio de 2001. Tejido congelado, alcohol y liofilizado.

MNCN/ADN: 10654. Valdemorillo. Madrid. 30 de junio de 2001. Tejido liofilizado.

MNCN/ADN: 10705. Collado Villalba. Madrid. 4 de junio de 2002. Tejido congelado y liofilizado.

MNCN/ADN: 10713. Colmenar Viejo. Madrid. 25 de junio de 2002. Tejido congelado.

MNCN/ADN: 10715. San Lorenzod del Escorial. Madrid. 27 de julio de 2002. Tejido congelado.

MNCN/ADN: 10726. Colmenar Viejo. Madrid. 7 de junio de 2002. Tejido congelado y liofilizado.

MNCN/ADN: 10741. Chinchón. Madrid. 13 de agosto de 2001. Tejido liofilizado.

MNCN/ADN: 10753, 10754. Madrid. Tejido congelado y liofilizado.

Milvus milvus (Linnaeus, 1758)

MNCN/ADN: 3205. La Cabrera. Madrid. 16 de febrero de 2003. Tejido congelado.

MNCN/ADN: 10150. Quijorna. Madrid. 10 de julio de 2002. Tejido congelado.

MNCN/ADN: 10401. Madrid. Tejido congelado, alcohol y liofilizado.

Parabuteo unicinctus (Temminck, 1824)

MNCN/ADN: 10428. Torrejón de Ardoz. Madrid. 31 de julio de 2003. Tejido liofilizado.

MNCN/ADN: 10909. Madrid. Tejido liofilizado.

Pernis apivorus (Linnaeus, 1758)

MNCN/ADN: 3688. Prádena del Rincón. Madrid. 31 de julio de 2003. Tejido congelado, alcohol y liofilizado.

MNCN/ADN: 10397. Aluche. Madrid. Tejido congelado, alcohol y liofilizado.

MNCN/ADN: 10461. Chapinería. Madrid. 13 de agosto de 2000. Tejido congelado.

MNCN/ADN: 10751. Madrid. Tejido congelado y liofilizado.

MNCN/ADN: 10871. Madrid. Tejido liofilizado.

\section{Familia FALCONIDAE}

Falco columbarius Linnaeus, 1758

MNCN/ADN: 3513. Valdeacabeda. Madrid. 9 de mayo de 2003. Tejido congelado.

MNCN/ADN: 3516. Madrid. 8 de enero de 2003. Tejido congelado y liofilizados

MNCN/ADN: 10369. Mejorada del Campo. Madrid. 26 de noviembre de 2001. Tejido congelado y alcohol.

Falco naumanni Fleischer, 1818

MNCN/ADN: 611. Torrejón de Ardoz. Madrid. 6 de agosto de 2002. Tejido congelado.
MNCN/ADN: 1520. Madrid. 2 de mayo de 2002. Tejido congelado y liofilizado.

MNCN/ADN: 3597. Madrid. Tejido congelado.

MNCN/ADN: 3598. Pedrezuela. Madrid. 16 de julio de 2003. Tejido congelado.

MNCN/ADN: 6467. Miraflores de la Sierra. Madrid. 13 de julio de 2004. Tejido congelado.

MNCN/ADN: 6766. Colmenar Viejo. Madrid. 26 de julio de 2004. Tejido congelado.

MNCN/ADN: 6772. Madrid. 31 de julio de 2004. Tejido congelado.

MNCN/ADN: 10393. Vallecas. Madrid. 1 de agosto de 2000. Tejido congelado, alcohol y liofilizado.

MNCN/ADN: 10395. Vallecas. Madrid. 1 de agosto de 2000. Tejido congelado, alcohol y liofilizado.

MNCN/ADN: 10400. Vallecas. Madrid Tejido liofilizado.

MNCN/ADN: 10472. Vallecas. Madrid. 7 de agosto de 2000. Tejido congelado.

MNCN/ADN: 10658. Aranjuez. Madrid. 26 de febrero de 2002. Tejido congelado.

MNCN/ADN: 10739. Vallecas. Madrid. 13 de junio de 2001. Tejido congelado y liofilizado.

MNCN/ADN: 10740. Valdemoro. Madrid. 29 de julio de 2001. Tejido congelado y liofilizado.

MNCN/ADN: 10925. Madrid. Tejido liofilizado.

Falco peregrinus Tunstall, 1771

MNCN/ADN: 2374. Vallecas - Villa. Madrid. 22 de noviembre de 2002. Tejido congelado y alcohol

MNCN/ADN: 3486. Rivas-Vaciamadrid. Madrid. 21 de mayo de 2003. Tejido congelado.

MNCN/ADN: 3498. Madrid. 4 de junio de 2003. Tejido congelado.

MNCN/ADN: 3541. Valverde de Alcalá. Madrid. 5 de junio de 2003. Tejido congelado y liofilizado.

MNCN/ADN: 3550, 3845, 17916. Valverde de Alcalá. Madrid. 11 de junio de 2003. Tejido congelado.

MNCN/ADN: 10204, 17881. Madrid. Tejido congelado.

MNCN/ADN: 10210. Madrid. 22 de abril de 2002. Tejido congelado.

MNCN/ADN: 10709. Torres de la Alameda. Madrid. 27 de enero de 2001. Tejido congelado.

MNCN/ADN: 10143. Madrid. 05 de julio de 2002. Tejido congelado.

MNCN/ADN: 17920. Aldea del Fresno. Madrid. 31 de agosto de 2005. Tejido congelado.

Falco subbuteo Linnaeus, 1758

MNCN/ADN: 6798. El Vellón. Madrid. 23 de agosto de 2004. Tejido congelado.

MNCN/ADN: 10350. Peralejo. Madrid. 17 de abril de 2002. Tejido congelado, alcohol y liofilizado.

MNCN/ADN: 10411. Villaconejos. Madrid. 4 de septiembre de 2001. Tejido congelado y alcohol.

MNCN/ADN: 10440. Valdemaqueda. Madrid. 6 de agosto de 2003. Tejido liofilizado.

MNCN/ADN: 10738. Puerto de los Leones. Madrid. 30 de julio de 2001. Tejido congelado y liofilizado.

MNCN/ADN: 10857. Madrid. Tejido liofilizado.

Falco tinnunculus Linnaeus, 1758

MNCN/ADN: 616. Madrid. 29 de julio de 2002. Tejido congelado.

MNCN/ADN: 620. San Sebastián de los Reyes. Madrid. 1 de agosto de 2002. Tejido congelado.

MNCN/ADN: 633. Leganés. Madrid. 6 de agosto de 2002. Tejido congelado.

MNCN/ADN: 639, 640. Torrejón de Ardoz. Madrid. 14 de agosto de 2002. Tejido congelado.

MNCN/ADN: 641. Madrid. 14 de agosto de 2002. Tejido congelado.

MNCN/ADN: 643. Cienpozuelos. Madrid. 14 de agosto de 2002. Tejido congelado.

MNCN/ADN: 644. Parla. Madrid. 14 de agosto de 2002. Tejido congelado. MNCN/ADN: 645. Madrid. 14 de agosto de 2002. Tejido congelado.

MNCN/ADN: 648. Pozuelo de Alarcón. Madrid. 14 de agosto de 2002. Tejido congelado.

MNCN/ADN: 649. Fuenlabrada. Madrid. 14 de agosto de 2002. Tejido congelado.

MNCN/ADN: 650. Fuenlabrada. Madrid. 14 de agosto de 2002. Tejido congelado. 
MNCN/ADN: 667. Madrid. 8 de agosto de 2002. Tejido congelado. MNCN/ADN: 684 al 686. Madrid. 26 de agosto de 2002. Tejido congelado. MNCN/ADN: 687. Buitrago de Lozoya. Madrid. 26 de agosto de 2002. Tejido congelado.

MNCN/ADN: 688. Madrid. 26 de agosto de 2002. Tejido congelado.

MNCN/ADN: 689. Alcobendas. Madrid. 26 de agosto de 2002. Tejido congelado.

MNCN/ADN: 690. Camarma de Esteruelas. Madrid. 26 de agosto de 2002. Tejido congelado.

MNCN/ADN: 691. Leganés. Madrid. 26 de agosto de 2002. Tejido congelado. MNCN/ADN: 692. Parla. Madrid. 26 de agosto de 2002. Tejido congelado.

MNCN/ADN: 693. Alcorcón. Madrid. 26 de agosto de 2002. Tejido congelado.

MNCN/ADN: 694. Madrid. 26 de agosto de 2002. Tejido congelado.

MNCN/ADN: 695. San Lorenzo del Escorial. Madrid. 26 de agosto de 2002. Tejido congelado.

MNCN/ADN: 696. Madrid. 26 de agosto de 2002. Tejido congelado.

MNCN/ADN: 697. Belmonte de Tajo. Madrid. 26 de agosto de 2002. Tejido congelado.

MNCN/ADN: 698. Madrid. 26 de agosto de 2002. Tejido congelado.

MNCN/ADN: 700. Getafe. Madrid. 26 de agosto de 2002. Tejido congelado.

MNCN/ADN: 1528. Fuenlabrada. Madrid. 25 de octubre de 202. Tejido congelado.

MNCN/ADN: 1534. Madrid. 7 de noviembre de 2002. Tejido congelado y alcohol.

MNCN/ADN: 2359. Madrid. 21 de junio de 2002. Tejido congelado.

MNCN/ADN: 2783. Rivas-Vaciamadrid. Madrid. 16 de enero de 2003 Tejido congelado.

MNCN/ADN: 2795. Madrid. 24 de enero de 2003. Tejido congelado.

MNCN/ADN: 3199, 3200. Aranjuez. Madrid. 10 de febrero de 2003. Tejido congelado.

MNCN/ADN: 3398. Torrejón de Ardoz. Madrid. 21 de marzo de 2003. Tejido congelado y liofilizado.

MNCN/ADN: 3469. Paracuellos del Jarama. Madrid. 9 de mayo de 2003. Tejido congelado alcohol y plumas.

MNCN/ADN: 3501. Fuenlabrada. Madrid. 28 de mayo de 2003. Tejido congelado.

MNCN/ADN: 3502. Pinto. Madrid. 28 de mayo de 2003. Tejido congelado.

MNCN/ADN: 3504. Navalcarnero. Madrid. 28 de mayo de 2003. Tejido congelado.

MNCN/ADN: 3509. Fuenlabrada. Madrid. 28 de marzo de 2003. Tejido congelado, alcohol y liofilizado.

MNCN/ADN: 3579. Madrid. 17 de julio de 2003. Tejido congelado.

MNCN/ADN: 3605. El Escorial. Madrid. 20 de julio de 2003. Tejido congelado y liofilizado.

MNCN/ADN: 3616. San Rafael. Madrid. 25 de julio de 2003. Tejido congelado.

MNCN/ADN: 3697. Algete. Madrid. 4 de agosto de 2003. Tejido congelado.

MNCN/ADN: 3842. Madrid. 29 de agosto de 2003. Tejido congelado.

MNCN/ADN: 3846. Aranjuez. Madrid. 29 de agosto de 2003. Tejido congelado.

MNCN/ADN: 3847, 3849. Madrid. 29 de agosto de 2003. Tejido congelado.

MNCN/ADN: 3850. Getafe. Madrid. 29 de agosto de 2003. Tejido congelado

MNCN/ADN: 3863. Barajas. Madrid. 24 de septiembre de 2003. Tejido congelado.

MNCN/ADN: 3884. San Agustín de Guadalix. Madrid. 28 de septiembre de 2003. Tejido congelado.

MNCN/ADN: 3885. Torrejón de Ardoz. Madrid. 8 de octubre de 2003. Tejido congelado.

MNCN/ADN: 3886. Torrelaguna. Madrid. 11 de octubre de 2003. Tejido congelado.

MNCN/ADN: 4181. Perales de Tajuña. Madrid. 9 de diciembre de 2003 Tejido congelado.

MNCN/ADN: 4184, 4185. Madrid. 17 de junio de 2003. Tejido congelado.

MNCN/ADN: 4192. Madrid. 20 de junio de 2003. Tejido congelado.

MNCN/ADN: 4194. Argando del Rey. Madrid. 19 de agosto de 2003. Tejido congelado.

MNCN/ADN: 4195. Humanes. Madrid. 19 de junio de 2003. Tejido congelado.

MNCN/ADN: 4196. Arganda del Rey. Madrid. 18 de enero de 2003. Tejido congelado.

MNCN/ADN: 4197. Aranjuez. Madrid. 4 de noviembre de 2003. Tejido congelado.
MNCN/ADN: 6699. Estremera. Madrid. 24 de agosto de 2004. Tejido congelado.

MNCN/ADN: 6704, 6705. Madrid. 10 de agosto de 2004. Tejido congelado.

MNCN/ADN: 6706. Humanes. Madrid. 10 de agosto de 2004. Tejido congelado.

MNCN/ADN: 6709. Madrid. 08 de agosto de 2004. Tejido congelado.

MNCN/ADN: 6714. Alcobendas. Madrid. 08 de agosto de 2004. Tejido congelado.

MNCN/ADN: 6720. Alcalá de Henares. Madrid. 10 de agosto de 2004. Tejido congelado.

MNCN/ADN: 6721. Colmenarejo. Madrid. 08 de agosto de 2004. Tejido congelado.

MNCN/ADN: 6722. Madrid. 08 de agosto de 2004. Tejido congelado.

MNCN/ADN: 6723. Fuenlabrada. Madrid. 10 de agosto de 2004. Tejido congelado.

MNCN/ADN: 6724. Fuenlabrada. Madrid. 08 de agosto de 2004. Tejido congelado.

MNCN/ADN: 6726. Madrid. 08 de agosto de 2004. Tejido congelado.

MNCN/ADN: 6756. Madrid. 10 de agosto de 2004. Tejido congelado.

MNCN/ADN: 6767. San Martín de la Vega. Madrid. 27 de julio de 2004. Tejido congelado.

MNCN/ADN: 6769. Madrid. 10 de agosto de 2004. Tejido congelado.

MNCN/ADN: 6770. Madrid. 28 de julio de 2004. Tejido congelado.

MNCN/ADN: 6815. Madrid. 21 de junio de 2004. Tejido congelado.

MNCN/ADN: 7097, 7098. Madrid. 2004. Tejido congelado. Tejido congelado.

MNCN/ADN: 7125, 10402 al 10405, 17878, 10858, 10865, 10919, 10926. Madrid. Tejido congelado.

MNCN/ADN: 7152. Madrid. 10 de diciembre de 2004. Tejido congelado

MNCN/ADN: 7153. Madrid. 02 de diciembre de 2004. Tejido congelado.

MNCN/ADN: 10133. Madrid. 29 de junio de 2002. Tejido congelado.

MNCN/ADN: 10140. Madrid. 07 de junio de 2002. Tejido congelado.

MNCN/ADN: 10144. Chichón. Madrid. 04 de julio de 2002. Tejido congelado.

MNCN/ADN: 10186. San Lorenzo del Escorial. Madrid. 20 de julio de 2002. Tejido congelado.

MNCN/ADN: 10244. Madrid. 21 de julio de 2001. Tejido congelado.

MNCN/ADN: 10245. Cienpozuelos. Madrid. 8 de mayo de 2002. Tejido congelado.

MNCN/ADN: 10257. Leganés. Madrid. 6 de mayo de 2002. Tejido congelado.

MNCN/ADN: 10391. Soto del Real. Madrid. 28 de agosto de 2001. Tejido congelado, alcohol y liofilizado.

MNCN/ADN: 10402 al 10404. Madrid. Tejido congelado, alcohol y liofilizado.

MNCN/ADN: 10405. Madrid. Tejido congelado y liofilizado

MNCN/ADN: 10417. Navacerrada. Madrid. 23 de junio de 2003. Tejido congelado, alcohol y liofilizado

MNCN/ADN: 10419, 10420. Madrid. 5 de julio de 2003. Tejido congelado y liofilizado.

MNCN/ADN: 10442. Móstoles. Madrid. 11 de agosto de 2003. Tejido congelado, alcohol y liofilizado.

MNCN/ADN: 10458. Madrid. 15 de agosto de 2000. Tejido congelado y liofilizado.

MNCN/ADN: 10459. Peralejo. Madrid. 10 de agosto de 2000. Tejido congelado alcohol.

MNCN/ADN: 10464. San Agustín de Guadalix. Madrid. 22 de agosto de 2000. Tejido congelado.

MNCN/ADN: 10493. Getafe. Madrid. 2 de abril de 2001. Tejido congelado y liofilizado.

MNCN/ADN: 10650. Barajas. Madrid. 30 de junio de 2000. Tejido congelado y liofilizado.

MNCN/ADN: 10659. Alcorcón. Madrid. 3 de abril de 2002. Tejido congelado.

MNCN/ADN: 10660. Fuenlabrada. Madrid. 28 de agosto de 2000. Tejido congelado.

MNCN/ADN: 10681. Madrid. 29 de junio de 2002. Tejido liofilizado. Tejido congelado y liofilizado.

MNCN/ADN: 10688. Perales de Tajuña. Madrid. 18 de julio de 2000. Tejido congelado y liofilizado.

MNCN/ADN: 10692. Fuentidueña de Tajo. Madrid. 30 de marzo de 2001. Tejido congelado y liofilizado.

MNCN/ADN: 10701. Sante Eugenia. Madrid. 2 de febrero de 2001. Tejido congelado y liofilizado.

MNCN/ADN: 10706. Las Matas. Madrid. 26 de mayo de 2001. Tejido congelado y liofilizado.

MNCN/ADN: 10714. Navalcarnero. Madrid. 5 de agosto de 2000. Tejido congelado y liofilizado. 
MNCN/ADN: 10786. Rascafría. Madrid. 10 de junio de 2002. Tejido congelado y liofilizado.

MNCN/ADN: 10788. Aranjuez. Madrid. 23 de mayo de 2002. Tejido congelado y liofilizado.

MNCN/ADN: 10806. San Lorenzo del Escorial. Madrid. Tejido congelado y liofilizado.

MNCN/ADN: 10807. Arganda del Rey. Madrid. 21 de mayo de 2000 Tejido congelado y liofilizado.

MNCN/ADN: 10809. Leganés. Madrid. 27 de febrero de 2002. Tejido congelado y liofilizado.

MNCN/ADN: 10858, 10865, 10919, 10926. Madrid. Tejido liofilizado.

MNCN/ADN: 10169. Madrid. 16 de julio de 2002. Tejido congelado

MNCN/ADN: 10187. Arganda del Rey. Madrid. 09 de julio de 2002. Tejido congelado

MNCN/ADN: 10188. Móstoles. Madrid. 10 de julio de 2002. Tejido congelado

MNCN/ADN: 17878. Madrid. Tejido congelado, alcohol y liofilizado.

MNCN/ADN: 17880. Patones de Abajo. Madrid. 19 de septiembre de 2005. Tejido congelado.

\section{Orden GALLIFORMES}

\section{Familia PHASIANIDAE}

Coturnix coturnix (Linnaeus, 1758)

MNCN/ADN: 6450. Peralejo. Madrid. 21 de junio de 2004. Tejido congelado. MNCN/ADN: 10208. Madrid. 11 de abril de 2002. Tejido congelado.

\section{Orden GRUIFORMES}

\section{Familia RALLIDAE}

Fulica atra Linnaeus, 1758

MNCN/ADN: 3871. Torrejón de Ardoz. Madrid. 18 de agosto de 2003 Tejido congelado.

MNCN/ADN: 6783. Colmenar Viejo. Madrid. 11 de agosto de 2004. Tejido congelado.

Gallinula chloropus (Linnaeus, 1758)

MNCN/ADN: 10455. Madrid. 11 de julio de 2003. Tejido congelado, alcohol y liofilizado.

Porphyrio porphyrio (Linnaeus, 1758)

MNCN/ADN: 10318. Aranjuez. Madrid. 4 de diciembre de 2000. Tejido congelado.

MNCN/ADN: 10320. Madrid. 23 de febrero de 2001. Tejido congelado.

Rallus aquaticus (Linnaeus, 1758)

MNCN/ADN: 6791. San Agustín de Guadalix. Madrid. 19 de agosto de 2004. Tejido congelado.

\section{Familia OTIDIDAE}

Otis tarda Linnaeus, 1758

MNCN/ADN: 677. Valdetorres de Jarama. Madrid. 19 de agosto de 2002 Tejido congelado y liofilizado.

MNCN/ADN: 1536. Valdemoro. Madrid. 4 de noviembre de 2002. Tejido congelado y alcohol.

MNCN/ADN: 3691. Valdetorres de Jarama. Madrid. 1 de agosto de 2003 Tejido congelado, alcohol y liofilizado.

MNCN/ADN: 3887. Ribatejada. Madrid. 6 de septiembre de 2003. Tejido congelado.

MNCN/ADN: 6411. Valdetorres de Jarama. Madrid. 15 de mayo de 2004 Tejido congelado.

MNCN/ADN: 6427. Campo Real. Madrid. 16/072004. Tejido congelado.

MNCN/ADN: 6451. Camarma de Esteruelas. Madrid. 09 de julio de 2004 Tejido congelado.

MNCN/ADN: 6468. Camarma de Esteruelas. Madrid. 16 de julio de 2004. Tejido congelado.

MNCN/ADN: 7120. Daganzo. Madrid. 20 de septiembre de 2004. Tejido congelado.

MNCN/ADN: 7132. Daganzo. Madrid. Tejido congelado.

MNCN/ADN: 10953. Madrid. Tejido liofilizado.

Tetrax tetrax (Linnaeus, 1758)

MNCN/ADN: 680. Paracuellos del Jarama. Madrid. 26 de agosto de 2002 Tejido congelado.
MNCN/ADN: 3566. Valdemoro. Madrid. 22 de julio de 2003. Tejido congelado.

MNCN/ADN: 10467. Titulcia. Madrid. 18 de agosto de 2000. Tejido congelado y alcohol.

MNCN/ADN: 17893. Colmenar de Oreja. Madrid. 12 de septiembre de 2005. Tejido congelado.

MNCN/ADN: 17912. Valdetorres de Jarama. Madrid. 19 de julio de 2005. Tejido congelado.

MNCN/ADN: 10881, 10882. Madrid. Tejido liofilizado.

\section{Orden CHARADRIIFORMES}

\section{Familia RECURVIROSTRIDAE}

Himantopus himantopus (Linnaeus, 1758)

MNCN/ADN: 3692. Paracuellos del Jarama. Madrid. 1 de agosto de 2003. Tejido congelado.

MNCN/ADN: 6443. Pinto. Madrid. 8 de julio de 2004. Tejido congelado.

\section{Familia BURHINIDAE}

Burhinus oedicnemus (Linnaeus, 1758)

MNCN/ADN: 671. Móstoles. Madrid. 14 de agosto de 2002. Tejido congelado, alcohol.

MNCN/ADN: 3203. Madrid. 15 de febrero de 2003. Tejido congelado.

MNCN/ADN: 3678. Aldea del Fresno. Madrid. 4 de agosto de 2003. Tejido congelado.

MNCN/ADN: 3679. Colmenar de la Oreja. Madrid. 4 de agosto de 2003. Tejido congelado.

MNCN/ADN: 3682. San Martín de la Vega. Madrid. 21 de agosto de 2003. Tejido congelado.

MNCN/ADN: 3840. Madrid. 29 de agosto de 2003. Tejido congelado.

MNCN/ADN: 7105. Madrid. 14 de diciembre de 2004. Tejido congelado

MNCN/ADN: 10134. Colmenar de Oreja. Madrid. 30 de junio de 2002.

MNCN/ADN: 10142. Vallecas. Madrid. 18 de julio de 2002. Tejido congelado.

MNCN/ADN: 10346. Manzanares el Real. Madrid. 18 de agosto de 2001. Tejido congelado, alcohol.

MNCN/ADN: 10451. Robledo de Chavela. Madrid. 8 de julio de 2003. Tejido liofilizado.

MNCN/ADN: 10466. Pozuelo. Madrid. 11 de agosto de 2000. Tejido congelado, alcohol.

MNCN/ADN: 10920. Madrid. Tejido liofilizado.

MNCN/ADN: 10944. Daganzo. Madrid. 22 de febrero de 2003. Tejido congelado y liofilizado.

MNCN/ADN: 10945. Torrejón de la Calzada. Madrid. 26 de diciembre de 2003. Tejido congelado y liofilizado.

MNCN/ADN: 10952. Madrid. Tejido liofilizado.

Familia CHARADRIIDAE

Charadrius dubius Scopoli, 1786

MNCN/ADN: 10904. Madrid. Tejido liofilizado.

Vanellus vanellus (Linnaeus, 1758)

MNCN/ADN: 7146. Manzanares el Real. Madrid. 13 de noviembre de 2004. Tejido congelado.

MNCN/ADN: 10348. Chinchón. Madrid. 29 de diciembre de 2001. Tejido congelado, alcohol y liofilizado.

MNCN/ADN: 10942. Loeches. Madrid. 28 de diciembre de 2001. Tejido congelado y liofilizado.

Familia SCOLOPACIDAE

Scolopax rusticola Linnaeus, 1758

MNCN/ADN: 10365. Madrid. Tejido liofilizado.

MNCN/ADN: 10886. Madrid. Tejido liofilizado.

\section{Familia LARIDAE}

Larus fuscus Linnaeus, 1758

MNCN/ADN: 2373. Meco. Madrid. 22 de noviembre de 2002. Tejido congelado y alcohol.

MNCN/ADN: 7129. Manzanares el Real. Madrid. 27 de septiembre de 2004. Tejido congelado.

MNCN/ADN: 10939. Pinto. Madrid. 25 de enero de 2003. Tejido congelado, alcohol y liofilizado.

MNCN/ADN: 17901. Manzanares del Real. Madrid. 27 de septiembre de 2004. Tejido congelado. 
Larus ridibundus Linnaeus, 1766

MNCN/ADN: 2360. Villaverde. Madrid. 27 de noviembre de 2002. Tejido congelado.

MNCN/ADN: 3201. Villalba. Madrid. 21 de febrero de 2003. Tejido congelado.

MNCN/ADN: 4186. Manzanares el Real. Madrid. 26 de septiembre de 2003. Tejido congelado.

MNCN/ADN: 4210. Valdemorillo. Madrid. 13 de diciembre de 2003. Tejido congelado.

MNCN/ADN: 6807. Manzanares El Real. Madrid. 08 de septiembre de 2004. Tejido congelado.

MNCN/ADN: 7102. Madrid. 3 de noviembre de 2004. Tejido congelado.

MNCN/ADN: 7137. Manzanares el Real. Madrid. 07 de octubre de 2004 Tejido congelado.

MNCN/ADN: 10848 al 10850. Arganda del Rey. Madrid. Tejido liofilizado.

MNCN/ADN: 17934. Algete. Madrid. 10 de febrero de 2002. Tejido congelado.

MNCN/ADN: 17937. Madrid. 09 de enero de 2002. Tejido congelado.

\section{Orden COLUMBIFORMES}

\section{Familia PTEROCLIDAE}

Pterocles orientalis (Linnaeus, 1758)

MNCN/ADN: 681. Algete. Madrid. 23 de agosto de 2002. Tejido congelado. Tejido congelado.

MNCN/ADN: 1522. Santa $\mathrm{M}^{\mathrm{a}}$. de la Alameda. Madrid. 13 de octubre de 2002. Tejido congelado

\section{Familia COLUMBIDAE}

Columba livia Gmelin, 1789

MNCN/ADN: 17940. Villanueva del Pardillo. Madrid. 31 de octubre de 2004. Tejido congelado.

Columba palumbus Linnaeus, 1758

MNCN/ADN: 4204. Canencia. Madrid. 3 de noviembre de 2003. Tejido congelado.

MNCN/ADN: 6465. Madrid. 23 de julio de 2004. Tejido congelado.

MNCN/ADN: 10943. Villanueva de la Cañada. Madrid. 20 de mayo de 2003. Tejido congelado y liofilizado.

Streptopelia decaocto (Frivaldszky, 1838)

MNCN/ADN: 17899. Alcalá de Henares. Madrid. 22 de octubre de 2004. Tejido congelado.

Streptopelia turtur (Linnaeus, 1758)

MNCN/ADN: 10936. Madrid Tejido liofilizado.

\section{Orden CUCULIFORMES}

\section{Familia CUCULIDAE}

Cuculus canorus Linnaeus, 1758

MNCN/ADN: 6456. Miraflores de la Sierra. Madrid. 03 de julio de 2004 Tejido congelado.

MNCN/ADN: 10473. Siete Iglesias. Madrid. 14 de agosto de 2000. Tejido congelado y liofilizado.

Clamator glandarius (Linnaeus, 1758)

MNCN/ADN: 6784. Zarzalejo. Madrid. 12 de agosto de 2004. Tejido congelado.

MNCN/ADN: 10429. El Vellón. Madrid. 26 de julio de 2003. Tejido congelado y liofilizado.

MNCN/ADN: 10471. Getafe. Madrid. 9 de agosto de 2000. Tejido congelado. MNCN/ADN: 17918. Peralejo. Madrid. 17 de julio de 2005. Tejido congelado.

\section{Orden STRIGIFORMES}

\section{Familia TYTONIDAE}

Tyto alba (Scopoli, 1769)

MNCN/ADN: 656. Cienpozuelos. Madrid. 14 de agosto de 2002. Tejido congelado.

MNCN/ADN: 2363. Aranjuez. Madrid. 1 de julio de 2002. Tejido congelado.

MNCN/ADN: 3551. Alcalá de Henares. Madrid. 11 de junio de 2003 Tejido congelado.
MNCN/ADN: 3573. Madrid. 30 de junio de 2003. Tejido congelado.

MNCN/ADN: 3607. Madrid. 25 de julio de 2003. Tejido congelado.

MNCN/ADN: 3615. Madrid. 25 de julio de 2003. Tejido congelado y liofilizado.

MNCN/ADN: 3861. San Lorenzo del Escorial. Madrid. 26 de agosto de 2003. Tejido congelado.

MNCN/ADN: 3862. Coslada. Madrid. 6 de octubre de 2003. Tejido congelado.

MNCN/ADN: 6792. El Berrueco. Madrid. 24 de agosto de 2004. Tejido congelado.

MNCN/ADN: 6814. Alcalá de Henares. Madrid. 12 de septiembre de 2004. Tejido congelado.

MNCN/ADN: 7144. Coslada. Madrid. 13 de octubre de 2004. Tejido congelado.

MNCN/ADN: 10201. Peralejo. Madrid. 17 de abril de 2002. Tejido congelado. MNCN/ADN: 10693. Torrejón de Ardoz. Madrid. 12 de febrero de 2001. Tejido congelado.

MNCN/ADN: 10718. Paracuellos del Jarama. Madrid. 26 de agosto de 2000. Tejido congelado y liofilizado.

MNCN/ADN: 10723. Villa del Prado. Madrid. 11 de septiembre de 2000. Tejido congelado y liofilizado.

MNCN/ADN: 10853, 10887, 10931 y 10933. Madrid. Tejido liofilizado.

MNCN/ADN: 17850. Madrid. Tejido congelado.

MNCN/ADN: 17868. San Fernando de Henares. Madrid. 10 de agosto de 2005. Tejido congelado.

MNCN/ADN: 17888. Buitrago de Lozoya. Madrid. 11 de agosto de 2005. Tejido congelado.

MNCN/ADN: 17905. Rozas de Puerto Real. Madrid. 24 de octubre de 2004. Tejido congelado.

Familia STRIGIDAE

Asio flammeus (Pontoppidan, 1763)

MNCN/ADN: 3548. Getafe. Madrid. 11 de junio de 2003. Tejido congelado. MNCN/ADN: 3563. Getafe. Madrid. 24 de junio de 2003. Tejido congelado.

MNCN/ADN: 10426. Aranjuez. Madrid. 24 de octubre de 2001. Tejido congelado, alcohol y liofilizado.

Asio otus (Linnaeus, 1758)

MNCN/ADN: 679. Parla. Madrid. 23 de agosto de 2002. Tejido congelado. MNCN/ADN: 3370. San Lorenzo del Escorial. Madrid. 15 de abril de 2003. Tejido congelado.

MNCN/ADN: 10200. San Sebastián de los Reyes. Madrid. 19 de abril de 2002. Tejido congelado.

MNCN/ADN: 10708. Madrid. 19 de junio de 2001. Tejido congelado y liofilizado.

MNCN/ADN: 17864. Barajas. Madrid. 5 de agosto de 2005. Tejido congelado.

Athene noctua (Scopoli, 1769)

MNCN/ADN: 619. Madrid. 30 de julio de 2002. Tejido congelado.

MNCN/ADN: 642. Madrid. 14 de agosto de 2002. Tejido congelado.

MNCN/ADN: 646. Pedrezuela. Madrid. 16 de agosto de 2002. Tejido congelado.

MNCN/ADN: 647. Madrid. 16 de agosto de 2002. Tejido congelado.

MNCN/ADN: 651. Moralzarzal. Madrid. 17 de julio de 2002. Tejido congelado y alcohol.

MNCN/ADN: 652. San Lorenzo del Escorial. Madrid. 12 de agosto de 2002. Tejido congelado y alcohol.

MNCN/ADN: 655. San Martín de la Vega. Madrid. 16 de agosto de 2002. Tejido congelado.

MNCN/ADN: 657. Madrid. 16 de agosto de 2002. Tejido congelado.

MNCN/ADN: 665. Chinchón. Madrid. 9 de agosto de 2002. Tejido congelado.

MNCN/ADN: 673. Torrejón de Ardoz. Madrid. 16 de agosto de 2002. Tejido congelado.

MNCN/ADN: 699. Pedrezuela. Madrid. 7 de octubre de 2002. Tejido congelado.

MNCN/ADN: 1518. Valdelaguna. Madrid. 4 de noviembre de 2002. Tejido congelado.

MNCN/ADN: 2362, 10916 al 10918, 10927 al 10929, 10949 al 10951, 17858. Madrid. Tejido congelado.

MNCN/ADN: 2371. Morata de Tajuña. Madrid. Tejido congelado. Tejido congelado.

MNCN/ADN: 3375. Aldea del Fresno. Madrid. 25 de abril de 2003. Tejido congelado.

MNCN/ADN: 3506. Chinchón. Madrid. 26 de mayo de 2003. Tejido congelado. 
MNCN/ADN: 3508. Manzanares el real. Madrid. 26 de mayo de 2003. Tejido congelado.

MNCN/ADN: 3511. Morata de Tajuña. Madrid. Tejido congelado.

MNCN/ADN: 3514. Torrejón de Ardoz. Madrid. 26 de mayo de 2003. Tejido congelado.

MNCN/ADN: 3540. San Martín de la Vega. Madrid. 6 de junio de 2003. Tejido congelado.

MNCN/ADN: 3586. Torrejón de Ardoz. Madrid. 10 de julio de 2003. Tejido congelado.

MNCN/ADN: 3595. Madrid. 14 de julio de 2003. Tejido congelado.

MNCN/ADN: 3677. Manzanares el Real. Madrid. 7 de agosto de 2003. Tejido congelado.

MNCN/ADN: 3687. Torrejón de Ardoz. Madrid. 21 de agosto de 2003. Tejido congelado.

MNCN/ADN: 3832. Chinchón. Madrid. 20 de octubre de 2003. Tejido congelado.

MNCN/ADN: 3833. Madrid. 20 de octubre de 2003. Tejido congelado.

MNCN/ADN: 3834. San Martín de la Vega. Madrid. 20 de octubre de 2003. Tejido congelado.

MNCN/ADN: 3835. Villamantilla. Madrid. 20 de octubre de 2003. Tejido congelado.

MNCN/ADN: 3836. Torrejón de Ardoz. Madrid. 20 de octubre de 2003. Tejido congelado.

MNCN/ADN: 4178. Morata de Tajuña. madrid. 3 de diciembre de 2003 Tejido congelado.

MNCN/ADN: 4200. Alcalá de Henares. Madrid. 23 de octubre de 2003. Tejido congelado.

MNCN/ADN: 6415. Madrid. 23 de julio de 2004. Tejido congelado.

MNCN/ADN: 6432. El Escorial. Madrid. 23 de julio de 2004. Tejido congelado.

MNCN/ADN: 6433. El Molar. Madrid. 23 de julio de 2004. Tejido congelado.

MNCN/ADN: 6763. Daganzo. Madrid. 23 de agosto de 2004. Tejido congelado.

MNCN/ADN: 6771. Peralejo. Madrid. 23 de agosto de 2004. Tejido congelado.

MNCN/ADN: 7131. Ribatejada. Madrid. 28 de septiembre de 2004. Tejido congelado.

MNCN/ADN: 7139. Cabanillas de la Sierra. Madrid. 10 de octubre de 2004. Tejido congelado.

MNCN/ADN: 10145. Algete. Madrid. 26 de junio de 2002. Tejido congelado.

MNCN/ADN: 10171. Alcobendas. Madrid. 13 de julio de 2002. Tejido congelado y liofilizado.

MNCN/ADN: 10182. Chinchón. Madrid. 23 de julio de 2002. Tejido congelado.

MNCN/ADN: 10195. Hoyo de Manzanares. Madrid. 12 de julio de 2002 Tejido congelado.

MNCN/ADN: 10441. Cerceda. Madrid. 10 de agosto de 2003. Tejido congelado y liofilizado.

MNCN/ADN: 10447. Perales del Río. Madrid. 28 de junio de 2003. Tejido liofilizado.

MNCN/ADN: 10448. Perales del Río. Madrid. 28 de junio de 2003. Tejido liofilizado.

MNCN/ADN: 10460. Peralejo. Madrid. 8 de agosto de 2000. Tejido congelado.

MNCN/ADN: 10468. Griñón. Madrid. 6 de agosto de 2000. Tejido congelado.

MNCN/ADN: 10470. Ajalvir. Madrid. 19 de agosto de 2000. Tejido congelado.

MNCN/ADN: 10478. Soto de Viñuelas. Madrid. 16 de julio de 2001 Tejido congelado y liofilizado.

MNCN/ADN: 10483. Rivas-Vaciamadrid. Madrid. 17 de julio de 2003 Tejido congelado y en alcohol.

MNCN/ADN: 10498. Madrid. 28 de mayo de 2000. Tejido congelado y liofilizado.

MNCN/ADN: 10499. Guadalix. Madrid. 27 de junio de 2000. Tejido congelado y liofilizado.

MNCN/ADN: 10673. Villaverde. Madrid. 30 de octubre de 2000. Tejido congelado y liofilizado.

MNCN/ADN: 10674. Villaverde. Madrid. 21 de septiembre de 2001. Tejido congelado y liofilizado.

MNCN/ADN: 10716. San Agustín de Guadalix. Madrid. 15 de julio de 2002. Tejido congelado.

MNCN/ADN: 10742. Alcalá Meco. Madrid. 27 de julio de 2001. Tejido congelado y liofilizado.
MNCN/ADN: 10743. San Lorenzo del Escorial. Madrid. 6 de agosto de 2001. Tejido congelado y liofilizado.

MNCN/ADN: 10744. Pedrezuela. Madrid. 25 de julio de 2001. Tejido congelado y liofilizado.

MNCN/ADN: 10745. Peralejos. Madrid. 24 de julio de 2001. Tejido congelado.

MNCN/ADN: 10773. Villa del Prado. Madrid. 6 de septiembre de 2000. Tejido congelado y liofilizado.

MNCN/ADN: 17858. Alcalá de Henares. Madrid. 1 de septiembre de 2005. Tejido congelado.

MNCN/ADN: 10916 al 10918, 10927 al 10929, 10949 al 10951. Madrid. Tejido congelado.

Bubo bubo (Linnaeus, 1758)

MNCN/ADN: 594 al 597. Aranjuez. Madrid. 2 de agosto de 2002. Tejido congelado.

MNCN/ADN: 599, 1510. Madrid. Tejido congelado. Tejido congelado.

MNCN/ADN: 602. Villaconejos. Madrid. 2 de agosto de 2002. Tejido congelado.

MNCN/ADN: 659. Chinchón. Madrid. 10 de agosto de 2002. Tejido congelado y alcohol.

MNCN/ADN: 727. Moralzarzal. Madrid. 9 de octubre de 2002. Tejido congelado y alcohol.

MNCN/ADN: 2353. Fresnedillas de la Oliva. Madrid. 23 de noviembre de 2002. Tejido congelado y liofilizado.

MNCN/ADN: 2361. Buitrago de Lozoya. Madrid. 5 de diciembre de 2002. Tejido congelado.

MNCN/ADN: 2368. Santorcaz. Madrid. 19 de noviembre de 2002. Tejido congelado y liofilizado.

MNCN/ADN: 2762. Robledo de Chavela. Madrid. Tejido congelado.

MNCN/ADN: 2764. Cienpozuelos. Madrid. 7 de diciembre de 2002. Tejido congelado.

MNCN/ADN: 2777. Villaviciosa de Odón. Madrid. 10 de enero de 2003. Tejido congelado.

MNCN/ADN: 2779. San Martín de la Vega. Madrid. 12 de enero de 2003. Tejido congelado.

MNCN/ADN: 3204. Chinchón. Madrid. 17 de febrero de 2003. Tejido congelado.

MNCN/ADN: 3214. Aldea del Fresno. Madrid. 15 de marzo de 2003. Tejido congelado.

MNCN/ADN: 3360. Bustarviejo. Madrid. 2 de abril de 2003. Tejido congelado.

MNCN/ADN: 3515. Cienpozuelos. Madrid. 8 de mayo de 2003. Tejido congelado.

MNCN/ADN: 3545. Collado Mediano. Madrid. 9 de junio de 2003. Tejido congelado.

MNCN/ADN: 3553. Chinchón. Madrid. 13 de junio de 2003. Tejido congelado, alcohol y liofilizado.

MNCN/ADN: 3606. Collado Mediano. Madrid. 24 de junio de 2003. Tejido congelado.

MNCN/ADN: 3698. Alcalá de Henares. Madrid. 5 de agosto de 2003. Tejido congelado y alcohol.

MNCN/ADN: 3870. Valdelatas. Madrid. 18 de septiembre de 2003. Tejido congelado.

MNCN/ADN: 3882. San Martín de Valdeiglesias. Madrid. 2 de octubre de 2003. Tejido congelado.

MNCN/ADN: 3883. Villaconejos. Madrid. 8 de octubre de 2003. Tejido congelado.

MNCN/ADN: 4206. Patones. Madrid. 4 de noviembre de 2003. Tejido congelado.

MNCN/ADN: 4213. Robledo de Chavela. Madrid. 13 de noviembre de 2003. Tejido congelado.

MNCN/ADN: 6413. Alcalá de Henares. Madrid. 2 de junio de 2004. Tejido congelado.

MNCN/ADN: 6422. Torrelaguna. Madrid. 8 de junio de 2004. Tejido congelado.

MNCN/ADN: 6431. Algete. Madrid. 30 de junio de 2004. Tejido congelado. MNCN/ADN: 6441. Torrelaguna. Madrid. 12 de junio de 2004. Tejido congelado.

MNCN/ADN: 6466. Colmenar Viejo. Madrid. 13 de julio de 2004. Tejido congelado.

MNCN/ADN: 6773. Colmenar Viejo. Madrid. 31 de julio de 2004. Tejido congelado. 
MNCN/ADN: 7084. Buitrago del Lozoya. Madrid. 07 de diciembre de 2004. Tejido congelado.

MNCN/ADN: 7096. Madrid. 2004. Tejido congelado.

MNCN/ADN: 7104. Villanueva de Perales. Madrid. 9 de noviembre de 2004. Tejido congelado.

MNCN/ADN: 7107. Alcalá de Henares. Madrid. 28 de octubre de 2004 Tejido congelado.

MNCN/ADN: 7123. Torres de la Alameda. Madrid. 23 de septiembre de 2004. Tejido congelado.

MNCN/ADN: 7138. Villanueva de Perales. Madrid. 10 de octubre de 2004 Tejido congelado.

MNCN/ADN: 10250. Navas del Rey. Madrid. Tejido congelado.

MNCN/ADN: 10265. Finca «La Boyeriza». San Martín de la Vega. Madrid. 5 de mayo de 2002. Tejido congelado.

MNCN/ADN: 10388. Tres Cantos. Madrid. 12 de septiembre de 2001. Tejido congelado, alcohol y liofilizado.

MNCN/ADN: 10425. Chapinería. Madrid. 19 de julio de 2003. Tejido congelado, alcohol y liofilizado.

MNCN/ADN: 10444. Piñuecar. Madrid. 9 de agosto de 2003. Tejido congelado y alcohol.

MNCN/ADN: 10657. Guadalix de la Sierra. Madrid. 19 de febrero de 2002. Tejido congelado y liofilizado.

MNCN/ADN: 10686. Chapinería. Madrid. 26 de agosto de 2001. Tejido congelado y liofilizado.

MNCN/ADN: 10704. Morata de Tajuña. Madrid. 23 de enero de 2001 Tejido congelado y liofilizado.

MNCN/ADN: 10748. Valdemorillo. Madrid. 23 de julio de 2001. Tejido liofilizado.

MNCN/ADN: 10760. Brunete. Madrid. Tejido congelado y liofilizado.

MNCN/ADN: 10774. Villa del Prado. Madrid. 25 de junio de 2001. Tejido congelado.

MNCN/ADN: 10775. Gandullas. Madrid. 13 de abril de 2001. Tejido liofilizado y congelado.

MNCN/ADN: 17896. Aranjuez. Madrid. 29 de enero de 2000. Tejido congelado.

MNCN/ADN: 17898. Brunete. Madrid. 15 de enero de 2000. Tejido congelado.

Otus scops (Linnaeus, 1758 )

MNCN/ADN: 598. Soto del Real. Madrid. 6 de agosto de 2002. Tejido congelado.

MNCN/ADN: 601. Gascones. Madrid. 6 de agosto de 2002. Tejido congelado.

MNCN/ADN: 612, 613. Madrid. 6 de agosto de 2002. Tejido congelado.

MNCN/ADN: 682, 683. Buitrago de Lozoya. Madrid. 26 de agosto de 2002. Tejido congelado.

MNCN/ADN: 717. Alpedrete. Madrid. 16 de septiembre de 2002. Tejido congelado.

MNCN/ADN: 724. Paracuellos del Jarama. Madrid. 8 de octubre de 2002 Tejido congelado.

MNCN/ADN: 3489. Navarredonda. Madrid. 24 de mayo de 2003. Tejido congelado.

MNCN/ADN: 3503. Madrid. 29 de mayo de 2003. Tejido congelado.

MNCN/ADN: 3505. Paracuellos del Jarama. Madrid. 7 de octubre de 2002 Tejido congelado y liofilizado.

MNCN/ADN: 3582. Collado Villalba. Madrid. 7 de julio de 2003. Tejido congelado.

MNCN/ADN: 3583. Berrocales del Jarama. Madrid. 9 de julio de 2003. Tejido congelado.

MNCN/ADN: 3602. Cervera de Buitrago. Madrid. 17 de julio de 2003. Tejido congelado y liofilizado.

MNCN/ADN: 3624. Madrid. 28 de julio de 2003. Tejido congelado.

MNCN/ADN: 3683. Lozoya. Madrid. 18 de agosto de 2003. Tejido congelado y liofilizado.

MNCN/ADN: 3689. Alcalá de Henares. Madrid. 31 de julio de 2003. Tejido congelado.

MNCN/ADN: 3841, 3843. Soto del Real. Madrid. 29 de agosto de 2003 Tejido congelado.

MNCN/ADN: 3851. La Navata. Madrid. 29 de agosto de 2003. Tejido congelado.

MNCN/ADN: 3852. Ciudad Pegaso. Madrid. 29 de agosto de 2003. Tejido congelado.

MNCN/ADN: 3853. Tres Cantos. Madrid. 29 de agosto de 2003. Tejido congelado.
MNCN/ADN: 3854, 3855. Hoyo de Manzanares. Madrid. 29 de agosto de 2003. Tejido congelado.

MNCN/ADN: 3856. Soto del Real. Madrid. 29 de agosto de 2003. Tejido congelado.

MNCN/ADN: 3857. Alcalá de Henares. Madrid. 29 de agosto de 2003. Tejido congelado.

MNCN/ADN: 3858. Collado Villalba. Madrid. 29 de agosto de 2003. Tejido congelado.

MNCN/ADN: 3859. Villavieja del Lozoya. Madrid. 29 de agosto de 2003. Tejido congelado.

MNCN/ADN: 3860. San Lorenzo del Escorial. Madrid. 29 de agosto de 2003. Tejido congelado.

MNCN/ADN: 6462. Manzanares El Real. Madrid. 11 de julio de 2004. Tejido congelado.

MNCN/ADN: 6719. Nuevo Batzán. Madrid. 09 de agosto de 2004. Tejido congelado.

MNCN/ADN: 6729. Talamanca. Madrid. 09 de agosto de 2004. Tejido congelado.

MNCN/ADN: 6730. Alcalá de Henares. Madrid. 09 de agosto de 2004. Tejido congelado.

MNCN/ADN: 6731. Villavieja del Lozoya. Madrid. 09 de agosto de 2004. Tejido congelado.

MNCN/ADN: 6751. Manjirón. Madrid. 09 de agosto de 2004. Tejido congelado.

MNCN/ADN: 6762. Daganzo. Madrid. 09 de agosto de 2004. Tejido congelado.

MNCN/ADN: 6777. Alcalá de Henares. Madrid. 30 de agosto de 2004. Tejido congelado.

MNCN/ADN: 6780. San Agustín de Guadalix. Madrid. 30 de agosto de 2004. Tejido congelado.

MNCN/ADN: 6785. Canencia. Madrid. 14 de agosto de 2004. Tejido congelado.

MNCN/ADN: 6787. Bustarviejo. Madrid. 16 de agosto de 2004. Tejido congelado.

MNCN/ADN: 6802. Rascafría. Madrid. 01 de septiembre de 2004. Tejido congelado.

MNCN/ADN: 7093. Madrid. Tejido congelado.

MNCN/ADN: 10146. Soto del Real. Madrid. 01 de julio de 2002. Tejido congelado.

MNCN/ADN: 10161. Navacerrada. Madrid. 17 de julio de 2002. Tejido congelado.

MNCN/ADN: 10175. Mataelpino. Madrid. 15 de julio de 2002. Tejido congelado.

MNCN/ADN: 10198. San Fernando Henares. Madrid. 05 de julio de 2002. Tejido congelado.

MNCN/ADN: 10202. Tres Cantos. Madrid. 22 de abril de 2002. Tejido congelado y liofilizado.

MNCN/ADN: 10421. Cerceda. Madrid. 30 de junio de 2003. Tejido liofilizado.

MNCN/ADN: 10422. Navas del Rey. Madrid. 23 de julio de 2003. Tejido liofilizado.

MNCN/ADN: 10456. Torrejón de Ardoz. Madrid. 3 de mayo de 2002. Tejido congelado y liofilizado.

MNCN/ADN: 10690. Buitrago de Lozoya. Madrid. 29 de marzo de 2001. Tejido congelado y liofilizado.

MNCN/ADN: 10746. Moncloa. Madrid. 27 de julio de 2001. Tejido congelado y liofilizado.

MNCN/ADN: 10897, 10905, 10907, 10911, 10913, 10946, 10947. Madrid. Tejido liofilizado.

MNCN/ADN: 17833. Hoyo de Manzanares. Madrid. 29 de septiembre de 2003. Tejido congelado.

MNCN/ADN: 17923. Cabanillas de la Sierra. Madrid. 26 de julio de 2005. Tejido congelado.

Strix aluco Linnaeus, 1758

MNCN/ADN: 603. Tres Cantos. Madrid. 7 de agosto de 2002. Tejido congelado.

MNCN/ADN: 638. Madrid. 9 de agosto de 2002. Tejido congelado.

MNCN/ADN: 1815. Hoyo de Manzanares. Madrid. 7 de agosto de 2002. Tejido congelado.

MNCN/ADN: 3208. Rascafría. Madrid. 6 de marzo de 2003. Tejido congelado.

MNCN/ADN: 3377. La Pedriza. Madrid. 5 de mayo de 2003. Tejido congelado. 
MNCN/ADN: 3396. Aranjuez. Madrid. 25 de marzo de 2003. Tejido congelado.

MNCN/ADN: 3470. Madrid. 10 de mayo de 2003. Tejido congelado.

MNCN/ADN: 3533 al 3537. Aranjuez. Madrid. 6 de junio de 2003. Tejido congelado.

MNCN/ADN: 3538. Pozuelo de Alarcón. Madrid. 6 de junio de 2003. Tejido congelado.

MNCN/ADN: 3592. Bustarviejo. Madrid. 28 de julio de 2003. Tejido congelado.

MNCN/ADN: 3601. Aranjuez. Madrid. 28 de julio de 2003. Tejido congelado.

MNCN/ADN: 3620. Aranjuez. Madrid. 28 de julio de 2003. Tejido congelado y liofilizado.

MNCN/ADN: 3622. Manzanares el Real. Madrid. 28 de julio de 2003. Tejido congelado.

MNCN/ADN: 3628, 3630. Bustarviejo. Madrid. 28 de julio de 2003. Tejido congelado.

MNCN/ADN: 3629. Bustarviejo. Madrid. 24 de abril de 2003. Tejido congelado y liofilizado.

MNCN/ADN: 4207. Galapagar. Madrid. 10 de noviembre de 2003. Tejido congelado.

MNCN/ADN: 6799. San Lorenzo de El Escorial. Madrid. 25 de agosto de 2004. Tejido congelado.

MNCN/ADN: 10212. Robledo de Chavela. Madrid. 18 de abril de 2002 Tejido congelado.

MNCN/ADN: 10416. Navacerrada. Madrid. 13 de mayo de 2003. Tejido congelado y liofilizado.

MNCN/ADN: 10497. Chinchón. Madrid. 28 de junio de 2000. Tejido congelado y liofilizado.

MNCN/ADN: 10710. Soto del Real. Madrid. 5 de septiembre de 2000 Tejido congelado y liofilizado.

MNCN/ADN: 10720. Madrid. 1999. Tejido congelado y liofilizado.

MNCN/ADN: 10747. Madrid. 2 de agosto de 2001. Tejido congelado y liofilizado.

MNCN/ADN: 10930, 10955. Madrid. Tejido liofilizado.

MNCN/ADN: 17903. San Agustín de Guadalix. Madrid. 19 de septiembre de 2004. Tejido congelado.

\section{Orden CAPRIMULGIFORMES}

\section{Familia CAPRIMULGIDAE}

Caprimulgus europaeus Linnaeus, 1758

MNCN/ADN: 662. Oteruelo del Valle. Madrid. 11 de agosto de 2002. Tejido congelado y liofilizado.

MNCN/ADN: 3472. Madrid. 11 de mayo de 2003. Tejido congelado.

MNCN/ADN: 3473. El Cuadrón. Madrid. 12 de mayo de 2003. Tejido congelado.

MNCN/ADN: 3491. La Acebeda. Madrid. 26 de mayo de 2003. Tejido congelado.

MNCN/ADN: 3839. Camarma de Esteruelas. Madrid. 15 de octubre de 2003. Tejido congelado.

MNCN/ADN: 6816. Madrid. Tejido congelado.

MNCN/ADN: 10427. Madrid. Tejido liofilizado

MNCN/ADN: 10463. Madrid. 22 de agosto de 2000. Tejido congelado.

MNCN/ADN: 10477. Rozas de Puerto Real. Madrid. 16 de agosto de 2003.

Tejido congelado.

MNCN/ADN: 10836, 10866. Madrid. Tejido liofilizado.

MNCN/ADN: 17874. Villavieja del Lozoya. Madrid. 20 de agosto de 2005. Tejido congelado.

Caprimulgus ruficollis Temminck, 1820

MNCN/ADN: 669. Alcorcón. Madrid. 12 de agosto de 2002. Tejido congelado y liofilizado.

MNCN/ADN: 672. Torrejón de Ardoz. Madrid. 14 de agosto de 2002. Tejido congelado.

MNCN/ADN: 718. Madrid. 18 de septiembre de 2002. Tejido congelado.

MNCN/ADN: 10697. Alcobendas. Madrid. 9 de agosto de 2000. Tejido congelado y liofilizado.

MNCN/ADN: 10899 al 10901. Madrid. Tejido liofilizado.

\section{Orden APODIFORMES}

Familia APODIDAE

Apus apus (Linnaeus, 1758)

MNCN/ADN: 615. Manzanares el Real. Madrid. 28 de julio de 2002 Tejido congelado.
MNCN/ADN: 627. Madrid. 2 de agosto de 2002. Tejido congelado. MNCN/ADN: 630. Pinilla del Valle. Madrid. 3 de agosto de 2002. Tejido congelado.

MNCN/ADN: 631. Pinilla del Valle. Madrid. 4 de agosto de 2002. Tejido congelado.

MNCN/ADN: 632. Peralejo. Madrid. 6 de agosto de 2002. Tejido congelado. MNCN/ADN: 634. Lozoya. Madrid. 6 de agosto de 2002. Tejido congelado. MNCN/ADN: 635. Horcajo de la Sierra. Madrid. 6 de agosto de 2002. Tejido congelado.

MNCN/ADN: 658. Madrid. 12 de agosto de 2002. Tejido congelado.

MNCN/ADN: 661. Horcajo de la Sierra. Madrid. 10 de agosto de 2002. Tejido congelado.

MNCN/ADN: 666. El Molar. Madrid. 9 de agosto de 2002. Tejido congelado. MNCN/ADN: 3379. El Escorial. Madrid. 2 de mayo de 2003. Tejido congelado.

MNCN/ADN: 3471. Miraflores de la Sierra. Madrid. 10 de mayo de 2003. Tejido congelado y liofilizado

MNCN/ADN: 3474. Móstoles. Madrid. 14 de mayo de 2003. Tejido congelado y liofilizado

MNCN/ADN: 3475. Madrid. 14 de mayo de 2003. Tejido congelado y liofilizado

MNCN/ADN: 3562. Madrid. 14 de julio de 2003. Tejido congelado y liofilizado.

MNCN/ADN: 3569. Madrid. 24 de junio de 2003. Tejido congelado.

MNCN/ADN: 3570. Coslada. Madrid. 26 de junio de 2003. Tejido congelado y liofilizado.

MNCN/ADN: 3588. San Agustín de Guadalix. Madrid. 11 de julio de 2003. Tejido congelado.

MNCN/ADN: 3589. Manzanares el Real. Madrid. 11 de julio de 2003. Tejido congelado.

MNCN/ADN: 3593. Soto del Real. Madrid. 14 de julio de 2003. Tejido congelado.

MNCN/ADN: 3594. Madrid. 14 de julio de 2003. Tejido congelado.

MNCN/ADN: 3596. Madrid. 16 de julio de 2003. Tejido congelado.

MNCN/ADN: 3599. Coslada. Madrid. 16 de julio de 2003. Tejido congelado.

MNCN/ADN: 3613. Madrid. 23 de julio de 2003. Tejido congelado.

MNCN/ADN: 3627. Madrid. 29 de julio de 2003. Tejido congelado.

MNCN/ADN: 3686. Loeches. Madrid. 11 de julio de 2003. Tejido congelado.

MNCN/ADN: 3690. Madrid. 30 de julio de 2003. Tejido congelado.

MNCN/ADN: 3694. Alcalá de Henares. Madrid. 4 de agosto de 2003.

Madrid. Tejido congelado.

MNCN/ADN: 6435. Madrid. 22 de junio de 2004. Madrid. Tejido congelado.

MNCN/ADN: 6440. Madrid. 11 de junio de 2004. Madrid. Tejido congelado.

MNCN/ADN: 6454. Madrid. 22 de junio de 2004. Madrid. Tejido congelado.

MNCN/ADN: 6455, 6457. Madrid. 03 de julio de 2004. Tejido congelado.

MNCN/ADN: 6725. Fuenlabrada. Madrid. 08 de agosto de 2004. Tejido congelado.

MNCN/ADN: 10151, 10154. Madrid. 23 de julio de 2002. Tejido congelado.

MNCN/ADN: 10170. Madrid. 11 de julio de 2002. Tejido congelado.

MNCN/ADN: 10173. Madrid. 17 de julio de 2002. Tejido congelado.

MNCN/ADN: 10174, 10177. Madrid. 14 de julio de 2002. Tejido congelado.

MNCN/ADN: 10184. Miraflores . Madrid. 25 de julio de 2002. Tejido congelado.

MNCN/ADN: 10193. Madrid. 2 de julio de 2002. Tejido congelado.

MNCN/ADN: 10243. Alcobendas. Madrid. 9 de mayo de 2002. Tejido congelado.

MNCN/ADN: 10923, 10924, 10954. Madrid. Tejido liofilizado.

MNCN/ADN: 17851. Buitrago de Lozoya. Madrid. 4 de agosto de 2005. Tejido congelado.

MNCN/ADN: 17853. Madrid. 31 de julio de 2005. Tejido congelado

MNCN/ADN: 17922. Madrid. 26 de julio de 2005. Tejido congelado.

MNCN/ADN: 17925. Madrid. 4 de agosto de 2005. Tejido congelado.

Apus pallidus (Shelley, 1855)

MNCN/ADN: 10937. Madrid. Tejido liofilizado.

Orden CORACIIFORMES

Familia MEROPIDAE

Merops apiaster Linnaeus, 1758

MNCN/ADN: 674. Cercedilla. Madrid. 16 de agosto de 2002. Tejido congelado.

MNCN/ADN: 3495. Tres Cantos. Madrid. 30 de mayo de 2003. Tejido congelado y liofilizado. 
MNCN/ADN: 3604. Madrid. 18 de julio de 2003. Tejido congelado. MNCN/ADN: 6793. El Escorial. Madrid. 20 de agosto de 2004. Tejido congelado.

MNCN/ADN: 6794. Manjirón. Madrid. 24 de agosto de 2004. Tejido congelado.

MNCN/ADN: 10196. San Lorenzo del Escorial. Madrid. 09 de julio de 2002. Tejido congelado.

MNCN/ADN: 10465. Guadalix. Madrid. 23 de agosto de 2000. Tejido congelado.

MNCN/ADN: 10687. Perales de Tajuña. Madrid. Tejido congelado y liofilizado.

MNCN/ADN: 10914, 10915, 10948. Madrid. Tejido liofilizado.

MNCN/ADN: 17931. Madrid. 14 de agosto de 2001. Tejido congelado.

\section{Familia CORACIIDAE}

Coracias garrulus Linnaeus, 1758

MNCN/ADN: 17921. Garganta de los Montes. Madrid. 21 de julio de 2005. Tejido congelado

Familia UPUPIDAE

Upupa epops Linnaeus, 1758

MNCN/ADN: 625. Manzanares del Real. Madrid. 1 de agosto de 2002. Tejido congelado.

MNCN/ADN: 10242. Guadalix de la Sierra. Madrid. 8 de mayo de 2002 Tejido congelado.

\section{Orden PICIFORMES}

\section{Familia PICIDAE}

Picoides major (Linnaeus, 1758)

MNCN/ADN: 3500. Peralejo. Madrid. 3 de junio de 2003. Tejido congelado.

MNCN/ADN: 7151. Alpedrete. Madrid. 12 de diciembre de 2004. Tejido congelado.

MNCN/ADN: 10415. Montejo de la Sierra. Madrid. 20 de junio de 2002 Tejido congelado, alcohol y liofilizado.

MNCN/ADN: 10446. Cercedilla. Madrid. 6 de julio de 2001. Tejido congelado y liofilizado.

MNCN/ADN: 10856. Madrid. Tejido liofilizado.

Picus viridis Linnaeus, 1758

MNCN/ADN: 3494. Madrid. 28 de mayo de 2003. Tejido congelado y liofilizado.

MNCN/ADN: 3557. Navas del Rey. Madrid. 23 de junio de 2003. Tejido congelado, alcohol y liofilizado.

MNCN/ADN: 3626. San Lorenzo del Escorial. Madrid. 29 de julio de 2003. Tejido congelado.

MNCN/ADN: 3700. Oteruelo del Valle. Madrid. 17 de agosto de 2003. Tejido congelado.

MNCN/ADN: 10324. Madrid. Octubre de 2001. Tejido congelado.

MNCN/ADN: 10325. Madrid. Octubre de 2001. Tejido congelado y alcohol.

MNCN/ADN: 10449. Madrid. 17 de junio de 2001. Tejido congelado, alcohol y liofilizado.

MNCN/ADN: 10476. La Navata. Madrid. 10 de noviembre de 2000. Tejido congelado.

MNCN/ADN: 10651. Pozuelo. Madrid. 16 de junio de 2000. Tejido congelado y liofilizado.

MNCN/ADN: 10902, 10956. Madrid. Octubre de 2001. Tejido liofilizado.

MNCN/ADN: 17854. Buitrago de Lozoya. Madrid. 11 de agosto de 2005. Tejido congelado.

MNCN/ADN: 17914. Carabanchel. Madrid. 26 de julio de 2005. Tejido congelado.

\section{Orden PASSERIFORMES}

Familia ALAUDIDAE

Lullula arborea (Linnaeus, 1758)

MNCN/ADN: 636. Alpedrete. Madrid. 8 de agosto de 2002. Tejido congelado.

Familia HIRUNDINIDAE

Delichon urbica (Linnaeus, 1758)

MNCN/ADN: 628. Madrid. 2 de agosto de 2002. Tejido congelado.

MNCN/ADN: 3877. San Lorenzo del Escorial. Madrid. 26 de agosto de 2003. Tejido congelado.
MNCN/ADN: 10172. Madrid. 13 de julio de 2002. Tejido congelado. MNCN/ADN: 10487. Madrid. 19 de julio de 2001. Tejido liofilizado.

MNCN/ADN: 10494. Hoyo de Manzanares. Madrid. 7 de julio de 2001. Tejido congelado y liofilizado.

MNCN/ADN: 17866. Buitrago de Lozoya. Madrid. 4 de agosto de 2005. Tejido congelado.

MNCN/ADN: 17924. Cervera de Buitrago. Madrid. 28 de julio de 2005. Tejido congelado.

Hirundo rustica Linnaeus, 1758

MNCN/ADN: 3467. Rivas-Vaciamadrid. Madrid. 7 de mayo de 2003. Tejido congelado y liofilizado.

MNCN/ADN: 4254. Valdemarín. Carretera de la Coruña, km 10. Madrid. 9 de octubre de 2003. Tejido congelado.

MNCN/ADN: 10691. Buitrago de Lozoya. Madrid. 7 de abril de 2001. Tejido congelado.

MNCN/ADN: 17859. Buitrago de Lozoya. Madrid. 22 de agosto de 2005. Tejido congelado.

\section{Familia MOTACILLIDAE}

Anthus campestris (Linnaeus, 1758)

MNCN/ADN: 10361, 10362. Madrid. Tejido liofilizado.

Familia LANIIDAE

Lanius senator Linnaeus, 1758

MNCN/ADN: 614. Gascones. Madrid. 28 de julio de 2002. Tejido congelado.

MNCN/ADN: 6732. Alcalá de Henares. Madrid. 14 de julio de 2004. Tejido congelado.

MNCN/ADN: 10885. Madrid. Tejido liofilizado.

\section{Familia CINCLIDAE}

Cinclus cinclus (Linnaeus, 1758)

MNCN/ADN: 10366. Madrid. Tejido liofilizado.

Familia EMBERIZIDAE

Emberiza cirlus Linnaeus, 1766

MNCN/ADN: 2768. Canencia. Madrid. 16 de diciembre de 2002. Tejido congelado.

Emberiza citrinella Linnaeus, 1758

MNCN/ADN: 4180. Rascafría. Madrid. 8 de diciembre de 2003. Tejido congelado.

\section{Familia TURDIDAE}

Erithacus rubecula (Linnaeus, 1758)

MNCN/ADN: 664. Zarzalejo. Madrid. 7 de agosto de 2002. Tejido congelado. MNCN/ADN: 10357. Madrid. Tejido liofilizado.

MNCN/ADN: 17935. Madrid. 17 de octubre de 2001. Tejido congelado.

MNCN/ADN: 17936. Alcalá de Henares. Madrid. 17 de noviembre de 2001. Tejido congelado.

Luscinia megarhynchos (Brehm, 1831)

MNCN/ADN: 4440. Madrid. 22 de abril de 2004. Tejido congelado.

Phoenicurus ochruros (Gmelin, 1774)

MNCN/ADN: 10359. Madrid. Tejido liofilizado.

MNCN/ADN: 17852. Buitrago de Lozoya. Madrid. 12 de agosto de 2005. Tejido congelado.

Turdus merula Linnaeus, 1758

MNCN/ADN: 3600. Madrid. 16 de julio de 2003. Tejido congelado. MNCN/ADN: 3699. Madrid. 6 de agosto de 2003. Tejido congelado.

MNCN/ADN: 3881. Robledo de Chavela. Madrid. 14 de octubre de 2003. Tejido congelado.

MNCN/ADN: 6445. San Agustín de Guadalix. Madrid. 17 de junio de 2004. Tejido congelado.

MNCN/ADN: 6447. La Cabrera. Madrid. 19 de junio de 2004. Tejido congelado.

MNCN/ADN: 6711. Buitrago de Lozoya. Madrid. 30 de agosto de 2004 Tejido congelado.

MNCN/ADN: 6757. Peralejo. Madrid. 19 de agosto de 2004. Tejido congelado.

MNCN/ADN: 6811. Móstoles. Madrid. 10 de septiembre de 2004. Tejido congelado. 
MNCN/ADN: 7092. Madrid. 20 de julio de 2004. Tejido congelado. MNCN/ADN: 10199. Colmenar Viejo. Madrid. 18 de abril de 2002. Tejido congelado.

MNCN/ADN: 10207. Peralejo. Madrid. 21 de abril de 2002. Tejido congelado.

MNCN/ADN: 10855. Madrid. Tejido liofilizado.

MNCN/ADN: 17856. Buitrago de Lozoya. Madrid. 12 de septiembre de 2005. Tejido congelado.

MNCN/ADN: 17933. Fuenlabrada. Madrid. 17 de noviembre de 2001. Tejido congelado.

Turdus philomelos Brehm, 1831

MNCN/ADN: 1529. La Hiruela. Madrid. 31 de octubre de 2002. Tejido congelado.

MNCN/ADN: 2778. Torremocha del Jarama. Madrid. 10 de enero de 2003 Tejido congelado.

MNCN/ADN: 4179. Villaverde Bajo. Madrid. 28 de noviembre de 2003. Tejido congelado.

MNCN/ADN: 4205. Gargantilla del Lozoya. Madrid. 1 de noviembre de 2003. Tejido congelado.

MNCN/ADN: 7150. La Cabrera. Madrid. 11 de diciembre de 2004. Tejido congelado.

MNCN/ADN: 10363, 10364. Madrid. Tejido liofilizado.

Familia SYLVIIDAE

Sylvia atricapilla (Linnaeus, 1758)

MNCN/ADN: 10353. Madrid. Tejido liofilizado.

Sylvia melanocephala (Gmelin, 1789)

MNCN/ADN: 10769. Robledo de Chavela. Madrid. 14 de agosto de 2003. Tejido congelado y liofilizado.

MNCN/ADN: 10770. Madrid. 14 de agosto de 2003. Tejido congelado.

\section{Familia MUSCICAPIDAE}

Ficedula hypoleuca (Pallas, 1764)

MNCN/ADN: 17846. Madrid. 6 de septiembre de 2005. Tejido congelado.

MNCN/ADN: 17847, 17848. Madrid. 5 de septiembre de 2005. Tejido congelado.

MNCN/ADN: . Madrid. 5 de septiembre de 2005. Tejido congelado.

MNCN/ADN: 17863, 17879, 17889. Madrid. Tejido congelado.

MNCN/ADN: 17894. La Acebeda. Madrid. 2 de septiembre de 2005. Tejido congelado.

Muscicapa striata (Pallas, 1764)

MNCN/ADN: 6898. Urbanización El Berrocal. Becerril de la Sierra. Madrid. 22 de septiembre de 2004. Tejido congelado.

Familia PARIDAE

Parus ater Linnaeus, 1758

MNCN/ADN: 17909. San Lorenzo del Escorial. Madrid. 2 de noviembre de 2004. Tejido congelado.

Parus caeruleus Linnaeus, 1758

MNCN/ADN: 4203. Colmenarejo. Madrid. 28 de octubre de 2003. Tejido congelado.

Parus major Linnaeus, 1758

MNCN/ADN: 10358. Madrid. Tejido liofilizado.

\section{Familia FRINGILLIDAE}

Carduelis carduelis (Linnaeus, 1758)

MNCN/ADN: 1532. Madrid. 9 de agosto de 2002. Tejido congelado.

MNCN/ADN: 3696. San Lorenzo del Escorial. Madrid. 4 de agosto de 2003. Tejido congelado.

MNCN/ADN: 4188. Madrid. Tejido congelado.

MNCN/ADN: 6795. Alcobendas. Madrid. 21 de agosto de 2004. Tejido congelado.

MNCN/ADN: 7121. Chinchón. Madrid. 1 de octubre de 2004. Tejido congelado.

MNCN/ADN: 7122. Madrid. Tejido congelado.

MNCN/ADN: 10197. Gascones. Madrid. 10 de julio de 2002. Tejido congelado.

MNCN/ADN: 10354 al 10356. Madrid. Tejido liofilizado.

MNCN/ADN: 10445. Gascones. Madrid. Tejido congelado.
Carduelis chloris (Linnaeus, 1758)

MNCN/ADN: 2782. Madrid. 14 de enero de 2003. Tejido congelado.

MNCN/ADN: 3695. Alcorcón. Madrid. 4 de agosto de 2003. Tejido congelado.

MNCN/ADN: 6417. Madrid. 4 de junio de 2004. Tejido congelado.

Fringilla coelebs Linnaeus, 1758

MNCN/ADN: 4209. Torremocha del Jarama. Madrid. 7 de noviembre de 2003. Tejido congelado.

MNCN/ADN: 10360. Madrid. Tejido liofilizado.

MNCN/ADN: 10772. Buitrago de Lozoya. Madrid. 6 de junio de 2003. Tejido congelado y liofilizado.

Loxia curvirostra Linnaeus, 1758

MNCN/ADN: 10694. Lozoyuela. Madrid. 3 de noviembre de 2001. Tejido congelado y liofilizado.

Serinus serinus (Linnaeus, 1766)

MNCN/ADN: 10176. Buitrago de Lozoya. Madrid. 12 de julio de 2002. Tejido congelado.

Familia PLOCEIDAE

Passer domesticus (Linnaeus, 1758)

MNCN/ADN: 1533. Buitrago de Lozoya. Madrid. 8 de noviembre de 2002. Tejido congelado.

MNCN/ADN: 2671. Madrid. 19 de septiembre de 2002. Tejido alcohol.

MNCN/ADN: 3497. Madrid. Tejido congelado.

MNCN/ADN: 6420. Madrid. 8 de junio de 2004. Tejido congelado.

MNCN/ADN: 6444. Buitrago de Lozoya. Madrid. 05 de julio de 2004. Tejido congelado.

MNCN/ADN: 6809. Buitrago de Lozoya. Madrid. 09 de septiembre de 2004. Tejido congelado.

MNCN/ADN: 10189. Madrid. 09 de julio de 2002. Tejido congelado.

MNCN/ADN: 10771. Madrid. 14 de agosto de 2003. Tejido congelado y liofilizado.

MNCN/ADN: 13514 al 13760. Collado Villalba. Madrid. 1993-1995. ADN.

Passer hispaniolensis (Temminck, 1820)

MNCN/ADN: 3196. Torrejón de Ardoz. Madrid. 4 de febrero de 2003. Tejido congelado.

MNCN/ADN: 6421. Rivas-Vaciamadrid. Madrid. 8 de junio de 2004. Tejido congelado.

Passer montanus (Linnaeus, 1758)

MNCN/ADN: 17915. Guadarrama. Madrid. 12 de noviembre de 2005. Tejido congelado.

Familia STURNIDAE

Sturnus unicolor Temminck, 1820

MNCN/ADN: 3490. Puentes Viejas. Madrid. 25 de mayo de 2003. Tejido congelado.

MNCN/ADN: 3493. Madrid. 28 de mayo de 2003. Tejido congelado, alcohol y liofilizado.

MNCN/ADN: 3552. Madrid. 12 de junio de 2003. Tejido congelado.

MNCN/ADN: 3625. Navacerrada. Madrid. 28 de julio de 2003. Tejido congelado.

MNCN/ADN: 3876. Villalba. Madrid. 27 de agosto de 2003. Tejido congelado.

MNCN/ADN: 6437. Barajas. Madrid. 11 de junio de 2004. Tejido congelado.

MNCN/ADN: 6701. Rivas-Vaciamadrid. Madrid. 19 de agosto de 2004. Tejido congelado.

MNCN/ADN: 10148. Collado Villalba. Madrid. 06 de julio de 2002. Tejido congelado.

MNCN/ADN: 10392. Soto del Real. Madrid. 7 de abril de 2003. Tejido congelado y alcohol.

MNCN/ADN: 10656. Peralejo. Madrid. 7 de abril de 2002. Tejido congeado y liofilizado.

MNCN/ADN: 17919. San Lorenzo del Escorial. Madrid. 17 de julio de 2005. Tejido congelado.

MNCN/ADN: 17886. Buitrago de Lozoya. Madrid. 20 de agosto de 2005. Tejido congelado. 
Familia ORIOLIDAE

Oriolus oriolus (Linnaeus, 1758)

MNCN/ADN: 3372. Robledo de Chavela. Madrid. 21 de abril de 2003. Tejido congelado y liofilizado.

MNCN/ADN: 3603. Fuentidueña de Tajo. Madrid. 18 de julio de 2003. Tejido congelado.

MNCN/ADN: 3610. Soto del Real. Madrid. 21 de julio de 2003. Tejido congelado y liofilizado.

MNCN/ADN: 7126. Madrid. 23 de septiembre de 2004. Tejido congelado.

MNCN/ADN: 10457. Soto del Real. Madrid. 4 de mayo de 2002. Tejido congelado y liofilizado.

MNCN/ADN: 10696. Buitrago de Lozoya. Madrid. 20 de agosto de 2000. Tejido congelado y liofilizado.

MNCN/ADN: 17885. Peralejo. Madrid. 22 de agosto de 2005. Tejido congelado.

Familia CORVIDAE

Corvus corone Linnaeus, 1758

MNCN/ADN: 10190. Madrid. 09 de julio de 2002. Tejido congelado y alcohol.

MNCN/ADN: 10370. Madrid. Tejido congelado y alcohol.

MNCN/ADN: 10655. Valdemorillo. Madrid. 30 de junio de 2001. Tejido liofilizado.

Corvus monedula Linnaeus, 1758

MNCN/ADN: 3574. Colmenar Viejo. Madrid. 22 de julio de 2003. Tejido congelado.

MNCN/ADN: 10132, 10685. Valdemorillo. Madrid. 30 de junio de 2002. Tejido congelado

MNCN/ADN: 10685. Valdemorillo. Madrid. 30 de junio de 2002. Tejido congelado y liofilizado.

Cyanopica cyana (Pallas, 1776)

MNCN/ADN: 618. Colmenar de Arroyo. Madrid. 30 de julio de 2002 Tejido congelado.

MNCN/ADN: 3556. Manjirón. Madrid. 23 de junio de 2003. Tejido congelado.

MNCN/ADN: 7124, 17904. Soto del Real. Madrid. 24 de noviembre de 2004. Tejido congelado.

Garrulus glandarius (Linnaeus, 1758)

MNCN/ADN: 10380. Madrid. Tejido liofilizado.

MNCN/ADN: 10495. Horcajuelo de la Sierra. Madrid. 10 de julio de 2001. Tejido liofilizado.

Pica pica (Linnaeus, 1758)

MNCN/ADN: 2804. Buitrago de Lozoya. Madrid. 3 de febrero de 2003. Tejido congelado.

MNCN/ADN: 3195. Torrejón de Ardoz. Madrid. 4 de febrero de 2003 Tejido congelado.

MNCN/ADN: 3543. Madrid. 6 de junio de 2003. Tejido congelado.

MNCN/ADN: 3612. Madrid. 23 de julio de 2003. Tejido congelado.

MNCN/ADN: 6414. Nuevo Baztan. Madrid. 2 de junio de 2004. Tejido congelado.

MNCN/ADN: 6416. Alcobendas. Madrid. 3 de junio de 2004. Tejido congelado.

MNCN/ADN: 6449. Peralejo. Madrid. 20 de junio de 2004. Tejido congelado.

MNCN/ADN: 6460. Somosierra. Madrid. 07 de julio de 2004. Tejido congelado.

MNCN/ADN: 6463. Alcalá de Henares. Madrid. 11 de julio de 2004 Tejido congelado.

MNCN/ADN: 6464. Alcalá de Henares. Madrid. 11 de julio de 2004 Tejido congelado.

MNCN/ADN: 6700. Becerril de la Sierra. Madrid. 09 de agosto de 2004 Tejido congelado.

MNCN/ADN: 6703. Madrid. 09 de agosto de 2004. Tejido congelado.

MNCN/ADN: 6727. Soto del Real. Madrid. 09 de agosto de 2004. Tejido congelado.

MNCN/ADN: 6788. Quijorna. Madrid. 16 de agosto de 2004. Tejido congelado.

MNCN/ADN: 10181. Buitrago de Lozoya. Madrid. 18 de julio de 2002 Tejido congelado.
MNCN/ADN: 10682. San Lorenzo del Escorial. Madrid. Tejido congelado y liofilizado.

MNCN/ADN: 17036. Madrid. Tejido congelado.

Pyrrhocorax pyrrhocorax (Linnaeus, 1758)

MNCN/ADN: 707. Rivas-Vaciamadrid. Madrid. 27 de agosto de 2002. Tejido congelado.

\section{MAMMALIA}

\section{Orden INSECTIVORA}

\section{Familia ERINACEIDAE}

Erinaceus europaeus Linnaeus, 1758

MNCN/ADN: 2370. San Fernando de Henares. Madrid. 27 de noviembre de 2002. Tejido congelado

MNCN/ADN: 3499. Collado Villalba. Madrid. 3 de junio de 2003. Tejido congelado

MNCN/ADN: 6713. Alcalá de Henares. Madrid. 06 de agosto de 2004 Tejido congelado

MNCN/ADN: 6755. San Sebastián de los Reyes. Madrid. 06 de agosto de 2004. Tejido congelado

MNCN/ADN: 6775. Robregordo. Madrid. 09 de septiembre de 2004. Tejido congelado

MNCN/ADN: 6779. Valdemoro. Madrid. 05 de agosto de 2004. Tejido congelado

MNCN/ADN: 10136. Aldea del Fresno. Madrid. 30 de julio de 2002. Tejido congelado

MNCN/ADN: 10166. Madrid. 02 de julio de2002. Tejido congelado

MNCN/ADN: 10454. Soto del Real. Madrid. 11 de agosto de 2003. Tejido congelado

MNCN/ADN: 10683. Aldea del Fresno. Madrid. 30 de junio de 2002. Tejido congelado

MNCN/ADN: 10689. Colmenar Viejo. Madrid. 8de marzo de 2001. Tejido congelado

\section{Familia SORICIDAE}

Crocidura russula (Hermann, 1780)

MNCN/ADN: 8934 al 8937. Arroyo de los Migueles. Rivas-Vaciamadrid. Madrid. 7 de agosto de2005. Tejido en alcohol

MNCN/ADN: 17083. Collado Mediano. Madrid. 2001. Tejido congelado

Sorex araneus Linnaeus, 1758

MNCN/ADN: 16953. Collado Mediano. Madrid. Tejido congelado

MNCN/ADN: 16958 al 16960. Collado Mediano. Madrid. 2001. Tejido congelado

MNCN/ADN: 16982 al 16984. Collado Mediano. Madrid. 2001. Tejido congelado

\section{Orden CHIROPTERA}

Familia VESPERTILIONIDAE

Pipistrellus pipistrellus (Schreber, 1774)

MNCN/ADN: 10149. San Lorenzo del Escorial. Madrid. 08 de julio de 2002. Tejido congelado

MNCN/ADN: 10206. Madrid. 17de abril de 2002. Tejido congelado

MNCN/ADN: 10695. Madrid. Madrid. 20 de febrero de 2001. Tejido congelado

MNCN/ADN: 17038. Pinto. Madrid. 17de abril de 2002. Tejido congelado

\section{Orden CARNIVORA}

Familia CANIDAE

Vulpes vulpes (Linnaeus, 1758)

MNCN/ADN: 2256, 2257. Madrid. Tejido liofilizado

MNCN/ADN: 3542. Madrid. Tejido congelado

MNCN/ADN: 3362 al 3364. Fuenlabrada. Madrid. 4 de abril de 2003. Tejido congelado

MNCN/ADN: 3369. Chapinería. Madrid. 12 de abril de 2003. Tejido congelado

MNCN/ADN: 3373. El Molar. Madrid. 20 de abril de 2003. Tejido congelado

MNCN/ADN: 4212. Bustarviejo. Madrid. 14 de noviembre de 2003. Tejido congelado 
MNCN/ADN: 6419. Collado Villalba. Madrid. 8 de junio de 2004. Tejido congelado

MNCN/ADN: 7103. Hoyo de Manzanares. Madrid. 6 de noviembre de 2004. Tejido congelado

MNCN/ADN: 7108. Rivas-Vaciamadrid. Madrid. 6 de noviembre de 2004. Tejido congelado

MNCN/ADN: 7136. Navalagamella. Madrid. 01 de octubre de 2004 Tejido congelado

MNCN/ADN: 10453. Chinchón. Madrid. 10 de julio de 2003. Tejido congelado y en alcohol

MNCN/ADN: 17867. Cenicientos. Madrid. 20 de septiembre de2005. Tejido congelado

\section{Familia FELIDAE}

Felis silvestris Schreber, 1775

MNCN/ADN: 3217. Navalagamella. Madrid. 20 de marzo de 2003. Tejido congelado

MNCN/ADN: 3680. Perales de Tajuña. Madrid. 15 de julio de 2003. Tejido congelado

MNCN/ADN: 4208. Cienpozuelos. Madrid. 7de noviembre de 2003. Tejido congelado

MNCN/ADN: 10215, 10216. Madrid. 16 de abril de 2002. Tejido congelado $\mathrm{y}$ en alcohol

\section{Familia HERPESTIDAE}

Herpestes ichneumon (Linnaeus, 1758)

MNCN/ADN: 3517. Villa del Prado. Madrid. 20 de mayo de 2003. Tejido liofilizado

Familia MUSTELIDAE

Lutra lutra (Linnaeus, 1758)

MNCN/ADN: 1539. Cadalso de los Vidrios. Madrid. 2de diciembre de 2002. Tejido congelado

MNCN/ADN: 3361. Navalagamella. Madrid. 4 de abril de 2003. Tejido congelado

MNCN/ADN: 3888. Navalagamella. Madrid. 2 de septiembre de 2003. Tejido congelado

MNCN/ADN: 10342. Lozoya. Madrid. 30 de marzo de 2002. Tejido congelado y en alcohol

MNCN/ADN: 17911. Villaviciosa de Odón. Madrid. 11 de julio de 2005. Tejido congelado

Martes foina (Erxleben, 1777)

MNCN/ADN: 3211. Talamanca del Jarama. Madrid. 15 de marzo de 2003. Tejido congelado

MNCN/ADN: 4182. Colmenar del Arroyo. Madrid. 10 de diciembre de 2003. Tejido congelado

MNCN/ADN: 4183. San Martín de Valdeiglesias. Madrid. 10d e diciembre de 2003. Tejido congelado

MNCN/ADN: 10412. Madrid. 8 de mayo de 2003. Tejido congelado y en alcohol

MNCN/ADN: 10439. Lozoyuela. Madrid. 13 de agosto de 2003. Tejido congelado y en alcohol

Meles meles (Linnaeus, 1758)

MNCN/ADN: 3210. Madrid. 10 de marzo de 2003. Tejido congelado

MNCN/ADN: 3487. San Lorenzo del Escorial. Madrid. 24 de mayo de 2003. Tejido congelado y en alcohol

MNCN/ADN: 10372. Madrid. 4 de abril de 2002. Tejido congelado y en alcohol

MNCN/ADN: 17871. Cabanillas de la Sierra. Madrid. 2 de septiembre de 2005. Tejido congelado

MNCN/ADN: 10217. Rascafría. Madrid. 04 de abril de 2002. Tejido congelado

Mustela erminea Linnaeus, 1758

MNCN/ADN: 17906. Cadalso de los Vidrios. Madrid. 10de julio de2002. Tejido congelado

Mustela putorius Linnaeus, 1758

MNCN/ADN: 1525. Alcalá de Henares. Madrid. 28 de octubre de 2002. Tejido congelado

MNCN/ADN: 2358. Madrid. Tejido congelado
MNCN/ADN: 10452. Madrid. Madrid. 10 de julio de 2002. Tejido congelado MNCN/ADN: 10474. Madrid. 18 de agosto de 2000. Tejido congelado

MNCN/ADN: 10482. Torrejón de Velasco. Madrid. 5 de junio de 2002. Tejido congelado

MNCN/ADN: 17944. Navas del Rey. Madrid. 10 de diciembre de 2004. Tejido congelado

Mustela vison Schreber, 1777

MNCN/ADN: 725. Lozoya. Madrid. 7 de octubre de 2002. Tejido congelado MNCN/ADN: 2797. Madrid. Madrid. 27de enero de 2003. Tejido congelado MNCN/ADN: 10680. Torrejón. Madrid. 2de abril de 2002. Tejido congelado

MNCN/ADN: 17840. Madrid. Tejido congelado

MNCN/ADN: 17986. Rascafría. Madrid. Tejido congelado

Familia VIVERRIDAE

Genetta genetta (Linnaeus, 1758)

MNCN/ADN: 3212. Fresnedilla de la Oliva. Madrid. 15 de marzo de 2003. Tejido congelado

\section{Orden ARTIODACTYLA}

\section{Familia SUIDAE}

Sus scrofa Linnaeus, 1758

MNCN/ADN: 10765, 10766. Rascafría. Madrid. 15 de diciembre de 2003. Tejido congelado

\section{Familia CERVIDAE}

Capreolus capreolus (Linnaeus, 1758)

MNCN/ADN: 1526. Manzanares el Real. Madrid. 1de enero de 2002.

MNCN/ADN: 1531. Miraflores de la Sierra. Madrid. 1de noviembre de 2002. Tejido congelado

MNCN/ADN: 2770. Lozoyuela. Madrid. 22 de octubre de 2002. Tejido congelado

MNCN/ADN: 3484. Rascafría. Madrid. 20 de mayo de 2003. Tejido congelado y en alcohol

MNCN/ADN: 6806. Torrelaguna. Madrid. 05 de septiembre de 2004. Tejido congelado

MNCN/ADN: 7149. La Hiruela. Madrid. 11 de diciembre de 2004. Tejido congelado

MNCN/ADN: 10160. El Atazar (El Berrueco). Madrid. 15 de julio de 2002. Tejido congelado

MNCN/ADN: 10218. Algete. Madrid. 27 de abril de 2002. Tejido congelado MNCN/ADN: 10398. Madrid. Tejido congelado y en alcohol

Cervus elaphus Linnaeus, 1758

MNCN/ADN: 1538. Lozoya. Madrid. 16 de septiembre de 2002. Tejido congelado

\section{Orden RODENTIA}

\section{Familia SCIURIDAE}

Sciurus vulgaris Linnaeus, 1758

MNCN/ADN: 623. Zarzalejo. Madrid. 31de julio de002. Tejido congelado MNCN/ADN: 1530. Madrid. 3de noviembre de 2002. Tejido congelado

MNCN/ADN: 1535. El Escorial. Madrid. 7de noviembre de 2002. Tejido congelado

MNCN/ADN: 2763. Las Rozas. Madrid. 10 de octubre de 2002. Tejido congelado

MNCN/ADN: 2771. Bustarviejo. Madrid. 22 de octubre de002. Tejido congelado

MNCN/ADN: 2792, 2793. Villaviciosa de Odón. Madrid. 21de enero de 2003. Tejido congelado

MNCN/ADN: 2794. Madrid. 22 de enero de 2003. Tejido congelado

MNCN/ADN: 3207. Rascafría. Madrid. 6 de marzo de 2003. Tejido congelado

MNCN/ADN: 3213. Madrid. Madrid. 26 de diciembre de 2003. Tejido congelado

MNCN/ADN: 3359. Bustarviejo. Madrid. 2 de abril de 2003. Tejido congelado

MNCN/ADN: 3366. Alcobendas. Madrid. 8 de abril de 2003. Tejido congelado

MNCN/ADN: 3367. San Lorenzo del Escorial. Madrid. 10 de abril de 2003. Tejido congelado 
MNCN/ADN: 3681. Soto del Real. Madrid. 17de julio de 2003. Tejido congelado

MNCN/ADN: 3693. San Lorenzo del Escorial. Madrid. 4 de agosto de 2003. Tejido congelado

MNCN/ADN: 4187. Madrid. Madrid. 26 de noviembre de 2003. Tejido congelado

MNCN/ADN: 4193. La Cabrera. Madrid. 18 de noviembre de 2003. Tejido congelado

MNCN/ADN: 6418. Collado Villalba. Madrid. 8 de junio de 2004. Tejido congelado

MNCN/ADN: 6428. Madrid. Madrid. 23 de julio de 2004. Tejido congelado

MNCN/ADN: 6804. San Agustín de Guadalix. Madrid. 02 de septiembre de 2004. Tejido congelado

MNCN/ADN: 6812. Peralejo. Madrid. 10 de septiembre de 2004. Tejido congelado

MNCN/ADN: 7086. La Cabrera. Madrid. 2de julio de 2004. Tejido congelado

MNCN/ADN: 7127. Rascafría. Madrid. 25 de septiembre de 2004. Tejido congelado

MNCN/ADN: 7128. Manzanares el Real. Madrid. 26 de septiembre de 2004. Tejido congelado

MNCN/ADN: 10152. Manzanares el Real. Madrid. 25de marzo de 2002. Tejido congelado

MNCN/ADN: 10153. Robledo de Chavela. Madrid. 25 de julio de 2002 Tejido congelado

MNCN/ADN: 10211. Alpedrete. Madrid. 09 de abril de 2002. Tejido congelado

MNCN/ADN: 10214. Torrelodones. Madrid. 18 de febrero de 2001. Tejido congelado

MNCN/ADN: 10240. El Escorial. Madrid. 7 de mayo de 2002. Tejido congelado

MNCN/ADN: 10246. San Lorenzo del Escorial. Madrid. 20 de mayo de 2002. Tejido congelado

MNCN/ADN: 10435. Manzanares el Real. Madrid. 27de junio de 2003. Tejido congelado

MNCN/ADN: 12395. Alpedrete. Madrid. 8 de febrero de 2005. Tejido congelado

MNCN/ADN: 17860. Manzanares el Real. Madrid. 8 de agosto de 2005 Tejido congelado

MNCN/ADN: 17875. Carabaña. Madrid. 6 de junio de 2005. Tejido congelado

MNCN/ADN: 17876. Rascafría. Madrid. 22 de agosto de 2005. Tejido congelado

MNCN/ADN: 17902. Rascafría. Madrid. 25 de septiembre de2004. Tejido congelado

MNCN/ADN: 17945. Alpedrete. Madrid. 18 de febrero de 2002. Tejido congelado

MNCN/ADN: 17946. San Agustín de Guadalix. Madrid. 4 de agosto de 2005. Tejido congelado
FAMILIA MURIDAE

Apodemus sylvaticus (Linnaeus, 1758)

MNCN/ADN: 4301. Manjirón. Madrid. Enero de 2003. Tejido congelado

MNCN/ADN: 4303 al 4306. Manjirón. Madrid. 24 de abril de 2003. Tejido congelado

MNCN/ADN: 4307 al 4312. Manjirón. Madrid. 13 de mayo de 2003. Tejido congelado

MNCN/ADN: 10221, 10222. Mataelpino. Madrid. 12 de julio de 2001. Tejido congelado y liofilizado

MNCN/ADN: 16952. Collado Mediano. Madrid. Agosto 2000. Tejido congelado

Microtus lusitanicus (Gerbe, 1879)

MNCN/ADN: 4253. Collado Mediano. Madrid. 2003. Tejido congelado

MNCN/ADN: 17007. Estación de Ferrocarril de El Goloso. Madrid. Tejido congelado

Mus musculus Linnaeus, 1758

MNCN/ADN: 10223. Collado Mediano. Madrid. Septiembre de 2001. Tejido congelado

MNCN/ADN: 16951. Collado Mediano. Madrid. Agosto de 2000. Tejido congelado

Familia MYOXIDAE

Eliomys quercinus (Linnaeus, 1766)

MNCN/ADN: 16954. Madrid. Tejido congelado y en alcohol

\section{Orden LAGOMORPHA}

Familia LEPORIDAE

Lepus granatensis Rosenhauer, 1856

MNCN/ADN: 4256. Alpedrete. Madrid. Marzo de 2002. Tejido congelado MNCN/ADN: 10124 al 10127. Daganzo. Madrid. 08 de julio de 1999. Tejido congelado

MNCN/ADN: 10128 al 10131. Camarma. Madrid. 16 de julio de 1999. Tejido congelado

Oryctolagus cuniculus (Linnaeus, 1758)

MNCN/ADN: 2772. Madrid. 22 de octubre de 2002. Tejido congelado

MNCN/ADN: 6796. Manjirón. Madrid. 21 de agosto de 2004. Tejido congelado

MNCN/ADN: 10247 al 10249. Valdemoro. Madrid. 3 de mayo de 2002. Tejido congelado 